\begin{tabular}{c} 
IUGJEPS \\
Vol 29, No 4, 2021, pp $435-462 \quad$ ISSN 2410-3152 $\quad$ مجلة الجامعة الإسلامية للاراسات التربوية والنفسية \\
\hline
\end{tabular}

تاريخ الإرسال (208-09-202)، تاريخ قبول النشر (2020-12)

دـ .منى هاشم محسن الزهراني

قسم المناهج وطرق التدريس، كلية التربية، جامعة الملك خالد، المملكة العربية السعودية

* البريد الالكتروني للباحث المرسل:

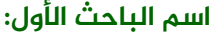

اسم الجامعة والبلد:

$$
\begin{aligned}
& \text { فعالية برنامج تلدريبي مقترح قتائم على } \\
& \text { التعلم النشط في تنمية مهارات التلدريس } \\
& \text { الإبلداعي للدى معلمات رياض الأطفال }
\end{aligned}
$$

E-mail address:

Malzhrani@kku.edu.sa

https://doi.org/10.33976/IUGJEPS.29.4/2021/18

| (الملنص:

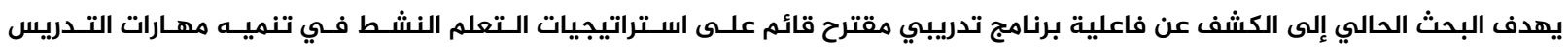

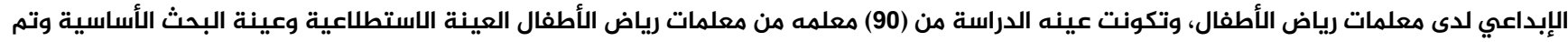

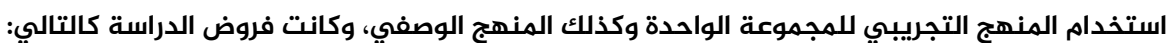

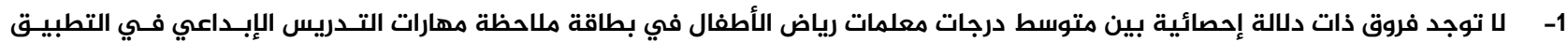

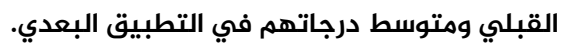

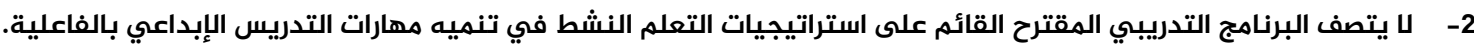
وكانت نتائج الدراسة كالتالي:

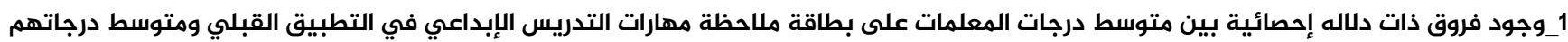
في التطبيق البعدي. 2-2 كلمات مفتاحية: التعلم النشط _ التدريس الإبداعي _ رياض الأطفال_ معلمة رياض الأطفال.

"Proposed training programme based on active learning to develop creative teaching skills of kindergarten teachers

\title{
Abstract:
}

The current research aims to determine the effectiveness of a proposed training programme based on active learning strategies in developing the creative teaching skills of kindergarten teachers. The study sample consisted of 50 kindergarten teachers. The pilot curriculum was used for the one group and the descriptive approach was used for study assignments.

1_There are no statistically significant differences between the average scores of kindergarten teachers on the card noting creative teaching skills in tribal application and their average scores in dimensional application.

2_The proposed training programme, based on active learning strategies, is not effective in developing innovative teaching skills.

The results of the study were as follows

1_There are statistically significant differences between the mean scores of kindergarten teachers on the card, noting creative teaching skills in tribal application, and the mean scores in dimension application.

. 2_ the proposed programme is effective

Keywords: (Active learning _ Creative teaching _ kindergarten_Kindergarten teachers) 


\section{أولاً-مقدمة البحث:}

التنكير الإبداعي ظاهرة راقيـة للنشاط الإنساني تنعكس آثارها على صـاحبها، وعلى المحيطين من حوله، فالإبداع هو نتاجاً جديداً وأصيلاً وذا قيمة، والإبداع لغة: مصطلح يشير إلى الجدة والأصالة واصطلاحاً: هو القدرة على إنتاج أثياء جديدة من عناصر قديمة، وهذه القدرة تتسم بالطلاقة والمرونة والأصالة. أو هو القدرة على إنشاء علاقات جديدة ومميزة بين أشياء موجودة بحيث لم تكن هذه العلاقات موجودة من

إن العصر الذي نعيش فيه الآن يتميز بثورة معلوماتية وتكنولوجية ومتغيرات سريعة وتطورات متعددة في كافة مجالات الحياة، ومن هنا

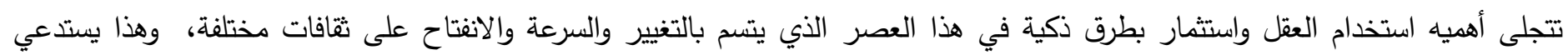
الاهتمام بالعقول المبدعة القادرة على إيجاد الحلول لكثير من المشكلات التي تهدد الفرد والمجتمع ، والتي تمكننا من مسايرة التطورات والتغيرات المتسارعة من أجل حسن التصرف والتكيف مع مختلف مناشط الحياة، ولتطبيق المعرفة في شتى قطاعات العندات العمل، وبالتالي فإن الاهتمام بتتمية

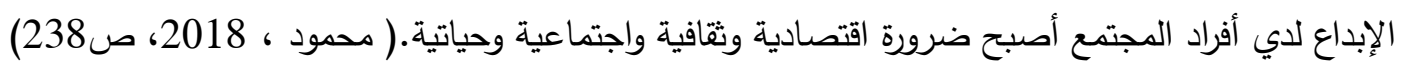

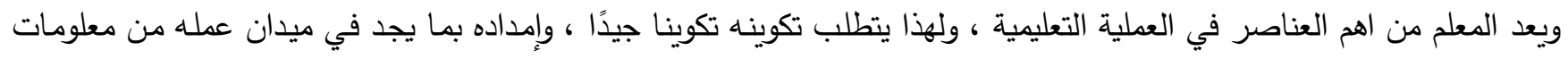

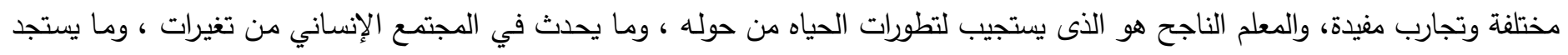

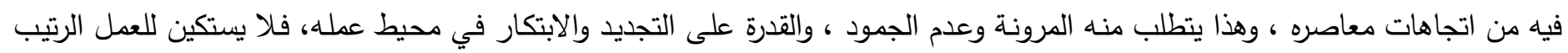

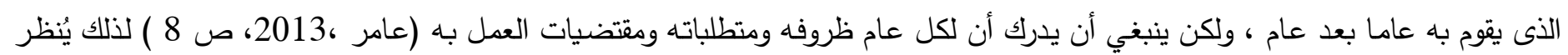

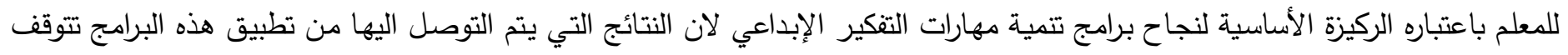

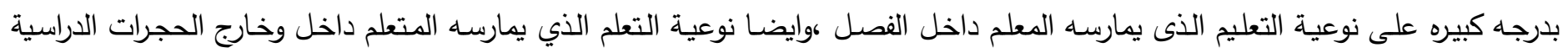
،الامر الذى يتطلب ضرورة تمكن المعلم من مهارات التدريس الإبداعي فكرا وسلوكا ووجدانا. ويعد التدريس الإبداعي أحد متطلبات العصر الحديث ،حيث يتطلب هذا العصر عقولا مبدعة قادرة على مواجهة التحديات المختلفة ، في شتى المجالات بطرق وأسـاليب جديدة ومتتوعـة (البنغلى وأبو السعيد،1996،ص التص 65)، وإذا كان الإبداع يتمثل في القدرة على اكتثاف

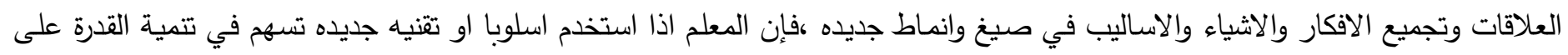
ربط واعادة تتظيم المعلومات والحقائق والافكار والعناصر لدى تلاميذه ،المتضمنة في الموقف التعليمي بطرق جديده تتسم بالطلاقة والمرونة والأصالة ،يكون المعلم عندئذ معلما مبدعا.

ولا يمكن وصف التدريس بانه تدريس إبداعي إذا فثل في تحقيق الأهداف التعليمية على أعلى مستوى وإذا عجز عن تتمية قدرة المتعلم

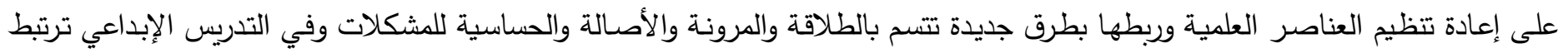
طرائق التدريس بأساليب الفكر المثيرة للجدل وبإدارة ديمقراطية النقاش وأحداث التعلم وتحقيق الدافعية للتعلم الذاتي وعليه يسير التدريس الإبداعي وإي ولئي

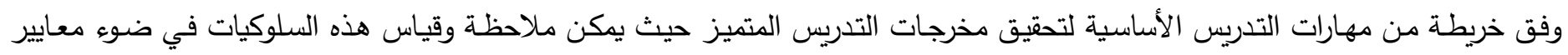
التعليم التي يجب مراعاتها في التعلم مصحوبة بمهارات التدريس الإبداعي القياسية المتفق عليها.

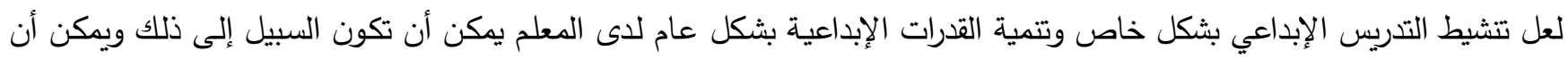

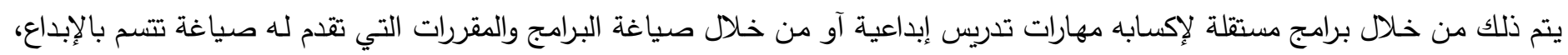

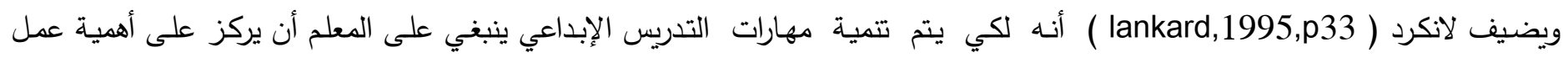

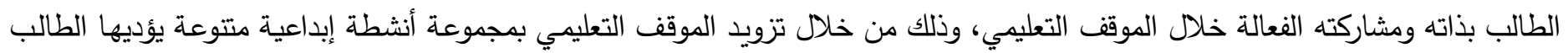


مع زيادة التركيز على الأبداع في العصر الحالي , فإن المعلمون بحاجة إلى أن يكونوا مهنيين مبدعين , فالمعلم هو محور أساسي في

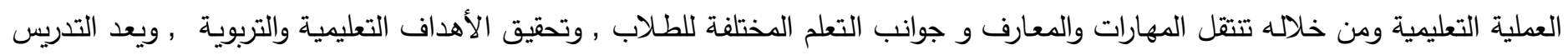

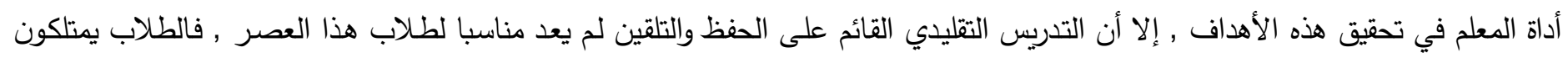

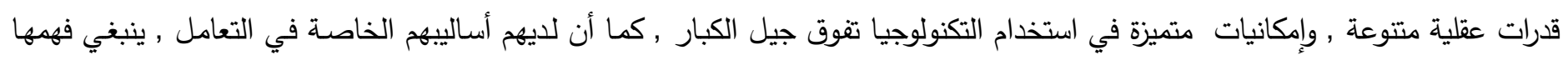

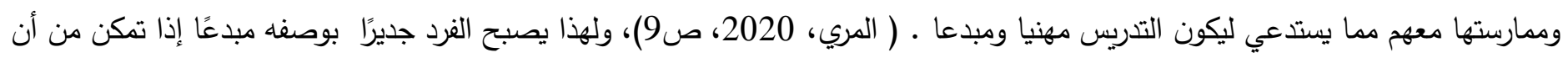

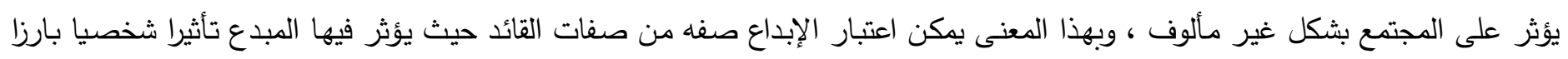

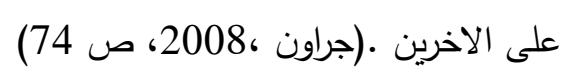
وأن حق القول بأن مهارات التدريس الإبداعية قد أصبحت ضرورين التروة ملحة في الوقت الراهن، فيسعى البحث الحالي الى إعداد برنامج

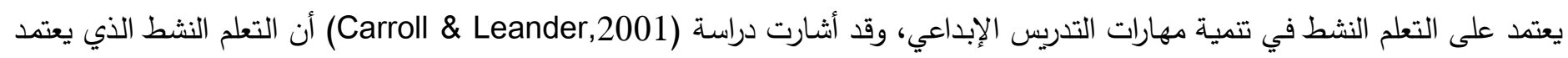
على استخدام الاستراتيجيات المتتوعة في الدرس الواحد تقلل من الأنثطة التعليمية السلبية مثل الإصغاء السلبي، وأخذ وتدوين الملاحظات طيلة وقت الحصة، وذلك بثكل يثير دافعيتهم للتعلم والانغماس فيها.

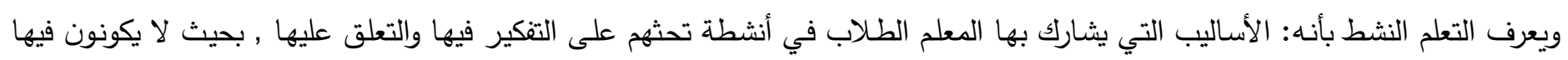
مجرد مستمعين , بل يطبقون المعرفة ويحللونها ويقُيمون المعلومات المقدة لهم عن طريق مناقثتها مع زملائهم , ويفكرون كثيرا في المعلومات

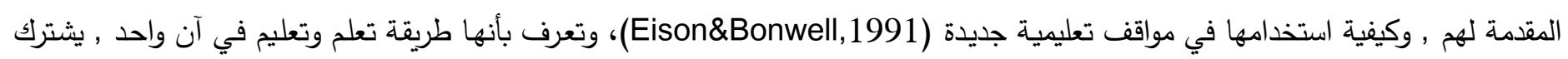
فيها الطلاب بأنشطة متتوعة تسمح لهم بالإصغاء الإيجابي والتنكير الواعي والتحليل السليم لمادة الدراسة , حيث يتثارك المتعلمون في الآراء

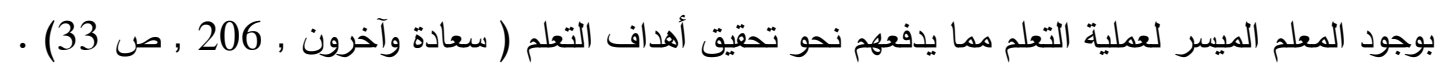

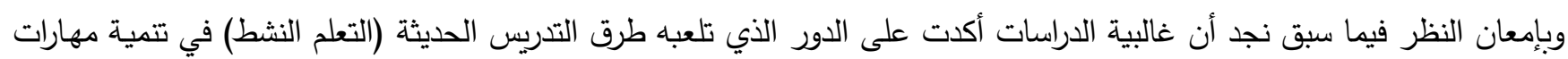

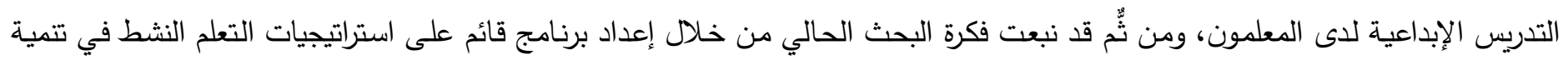
مهارات التدريس الإبداعي لاى معلمات رياض الأطفال. والتأكد من فعاليته. ثانياً- مشكلة البحث:

تتمثل مشكلة البحث الحالي في إنخفاض مستوى استخدام استراتيجيات التعلم النشط والذى قد يكون السبب في تدني مهارات التدريس الإبداعية لاى معلمي رياض الأطفال، ومن ثُّ ظهرت الحاجة لإعداد برنامج تدريبي قائم على التعلم النشط في تتمية مهارات التدريس الإبداعي

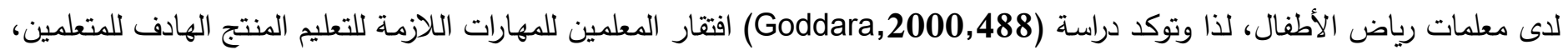

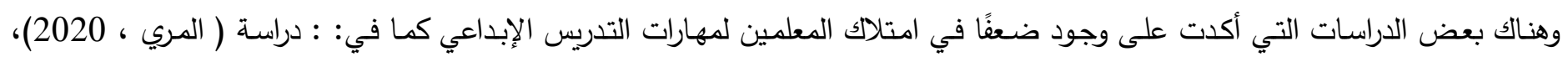

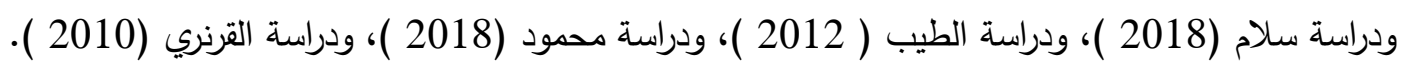
ويؤكد المتخصصون في الإبداع أنه ما لم يمتلك المعلم حدا أدنى من معامل الإبداع فإن ذلك ينعكس سلبيا على المتعلمين بعامة ،

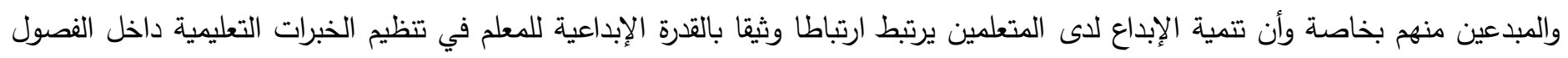

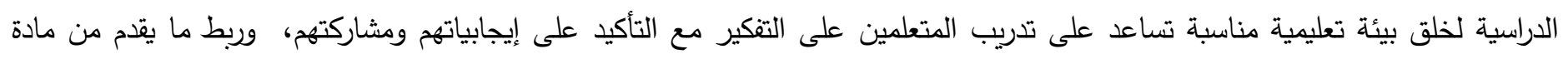

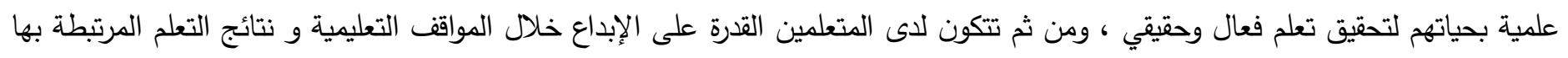
( محمود، 2018، 243 وقد أكدت دراسات عديدة على أهمية تدريب المعلمين على مهارات التدريس الإبداعي من خلال برامج تدريبية تتمي هذه المهارات، مثل:

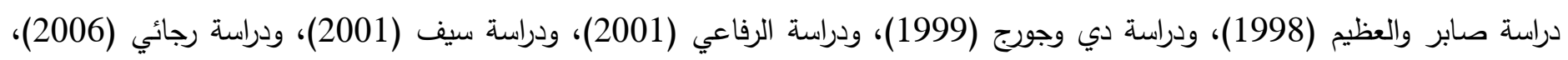

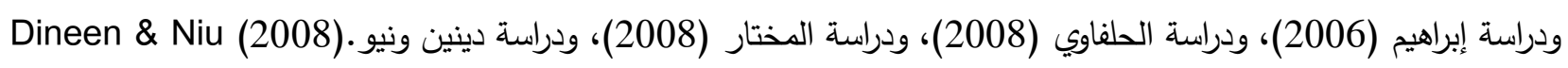


ويؤكد كل من جيفري وكرافت (Farrington , Gollisse ,2004) ضرورة التدريس بإبداع والتدريس للإبداع ، وأن كلاً المفهومين يتكاملان لنجاح ممارسة التدريس الجيد في الفصول الدراسية، فلا تعليم جيد بدون معلم جيد يمتلك فكرا إبداعي متقدما من أجل إنتاج متعلم

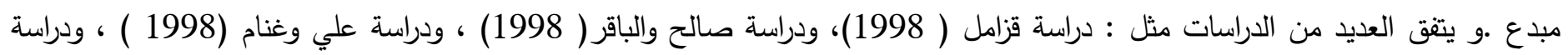

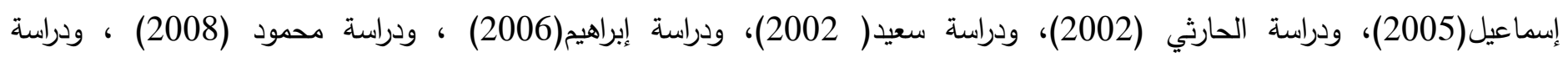

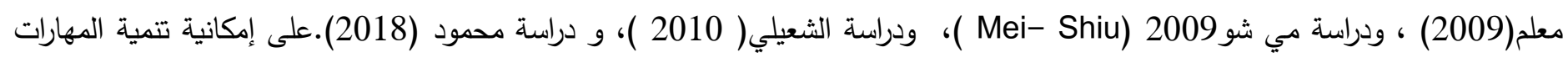
الإبداعية من خلال طرائق التدريس المستخدمة( التعلم النشط)، ومن خلال نتائج الدراسات السابقة يتضح أهميه تمكن المعلم من مهارات التدريس الإبداعي إذا أردنا تكوين جيل من المبدعين، وأن أسلوب أعداد المعلم له أثر كبير في مساعدته على القيام بدوره بفاعلية في المواقف التعليمية

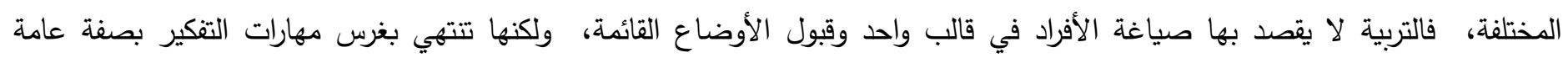

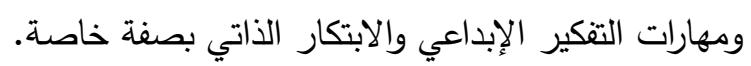
فالمعلم ينبغي أن يتمتع بإمكانات ومهارات تدريسية تمكنه من أداء هذا الدور مثل: مهارات طرح الأسئلة التي تتحدي تفكير المتعمين، و مهارات إدارة الفصل ومهارة معالجة المعلومات ومهارات تتسيق العمل بنشاط وإتاحة الفرصة أمام المتعلمين لإبداء الرأي والمناقثة والحوار وخلق جو انفعالي دافع يسهم في إثراء فكر المتعلمين ورفع عنهم مظاهر الحرج والقلق والخوف الذي عادة ما يصاحب الطرق التفكيرية

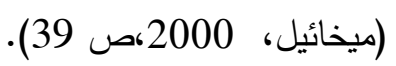
وأشار جابر عبد الحميد جابر إلى أن من متطلبات القرن الحادي والعشرين أن نساعد المتعمين على أن يبدعوا ويبتكروا، وهذا يستلزم

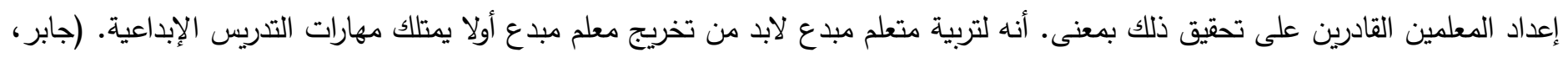

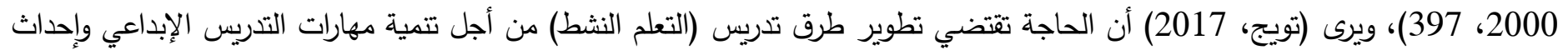
تطوير في تعلم الطلبة وتحقيق الأهداف التي تتركز في دعم وبناء المعاني العلمية، وقد جاءت هذه الدئ الدراسة والتي نأمل أن تحمل بين طياتها نتائج تقيد المتعلمين والمعلمين في أهمية استخدام استراتيجيات التعلم النشط لتتمية مهارات التدريس الإبداعية لدى معلمات رياض فلاض الأطفال.

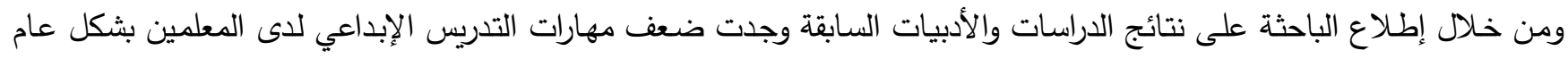

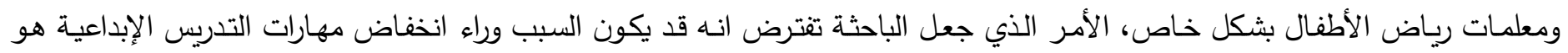
انخفاض مستوى استخدامهم لاستراتيجيات التعلم النشط، ومن ثم كانت هناك حاجة ماسة لإعداد برنامج تدريبي قائم على التعلم النشط في تتمية مهارات التدريس الإبداعية لدى معلمات رياض الأطفال بمنطقة عسير بالمملكة العببية السعودية والتأكد من فعالية هذا البرنامج. وتتلخص مشكلة البحث الحالي في التساؤل التالي:

1. ما مدى توافر مهارات التدريس الإبداعي لدى معلمات رياض الأطفال في التطبيق القبلي؟

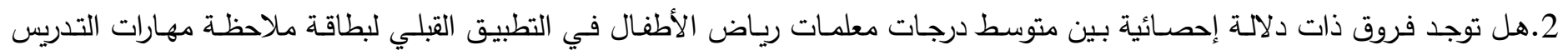

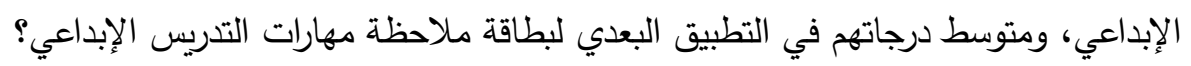

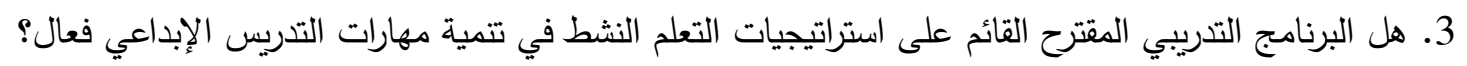

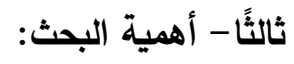
تتضح أهمية البحث في الجوانب النظرية والتطبيقية التالية:

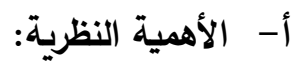
1. يفيد هذا البحث في إثراء الجانب النظري المتعلق بالتعلم النثط ومهارات التدريس الإبداعي.

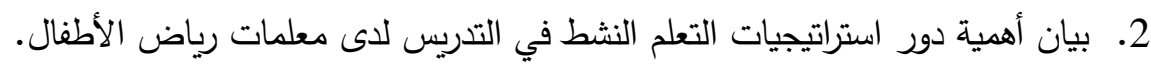
3. أهمية دور مهارات التدريس الإبداعي لدى معلمات رياض الأطفال في التدريس لأطفال مرحلة ما قبل المدرسة. 
يسعى البحث الحالي إلى تطوير الأداء التدريسي لمعلمات رياض الأطفال، ويتفرع من هذا الهدف الأهداف التاليه: 1- التعرف على مهارات التدريس الإبداعية ومستواها لاى عينة من معلمات رياض الإه الأطفال.

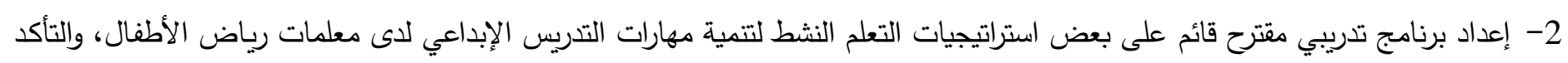
من فعاليته.

$$
\begin{aligned}
& \text { خامسًا - مصطلحات البحث: } \\
& \text { 1- البرنامج التدريبي: }
\end{aligned}
$$

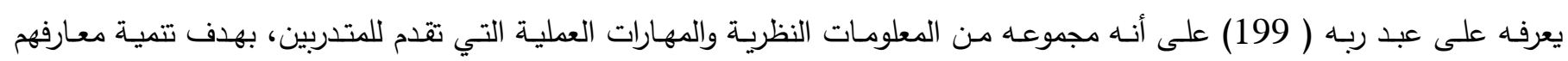

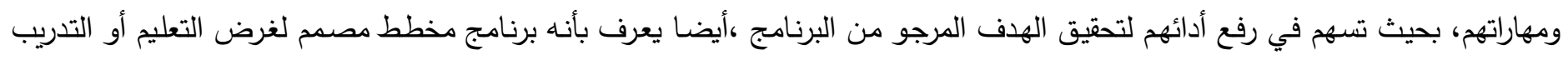

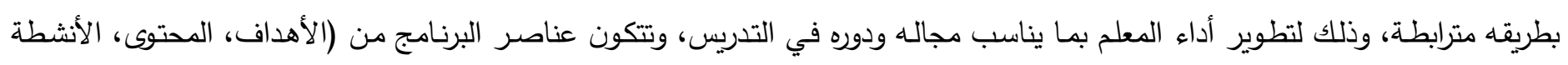

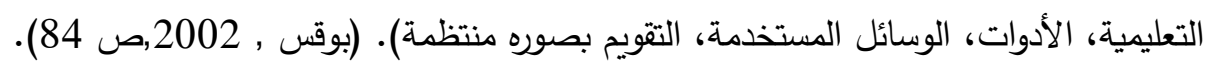
ويعرف اجرائيا بأنه مجموعة من الانثطة والمعارف التي تهدف الى اكساب المتدربين العديد من المهارات والخبرات التي تهدف الى تحسين ورفع كفاءتهم.

2- التعلم النشط: هو عباره عن التعلم الذى يجعل التلميذ مشارك بفاعليه في الموقف التعليمي من خلال ما يقوم به من قراءه وكتابه في عدة موضوعات

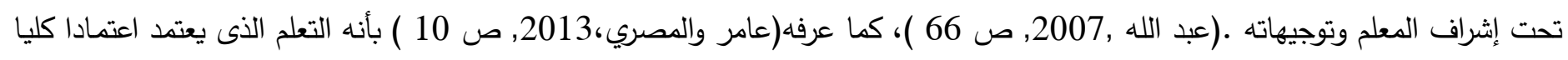

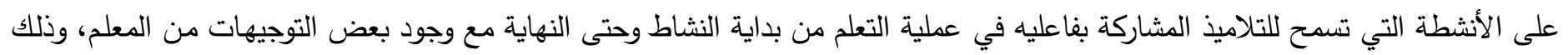

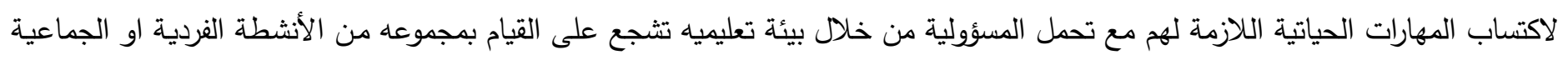

ويعرف اجرائيا بانه عبارة عن طريقة تدريس تهدف الى جعل المتعلم محور العملية التعليمية والذي يمكن تتميته من خلال البرنامج المعد

$$
\text { 3-التدرث الحالي. }
$$

يعرف بانه نمط من السلوك التدريسي الفعال الذي يستخدمه المعلم معتمدا فيه على قدراته الإبداعية لإحداث تفاعل تدريسي بينه وبين

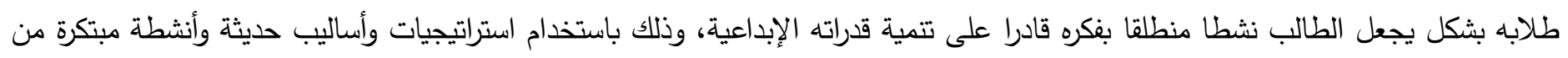
شأنها مساعدة الطالب على التفكير الإبداعي (سبع الليل ,2008, ص 25). وتتكون مهارات التدريس الإبداعي في البحث الحالي من أربع مهارات هي: (الإعداد الجيد للدرس، الأساليب الإبداعية للتدريس، والعرض المشوق، والتقويم الإبداعي) الإبل

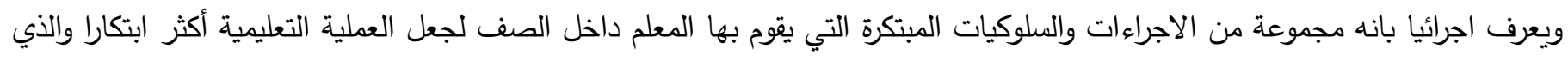

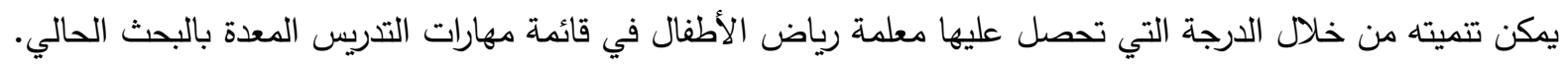




\section{4-معلمة رياض الأطفال:}

تعرف بأنها شخصية تربوية تم اختيارها بعناية بالغة من خلال مجموعة من المعايير الخاصـة بالسمات والخصائص الجسمية، العقلية،

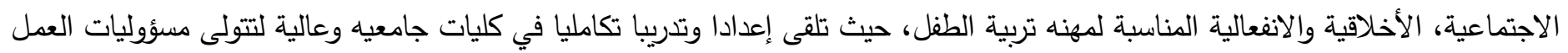

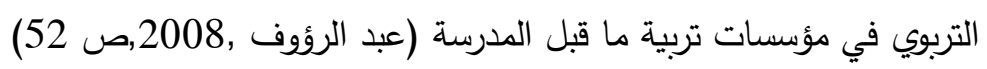

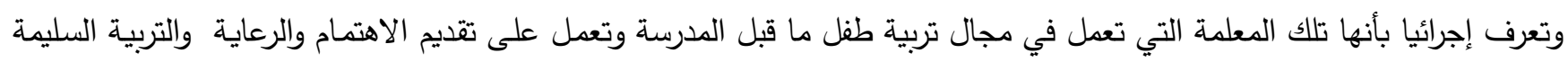
والاسهام في تتمية مدارك الطفل وصقل شخصيته من جميع الجوانب العقلية والجسمية والانفعالية واللغوية والدينية والاجتماعية. سادسًا - حدود البحث: أ. الحدود الموضوعية: يتتاول البحث متغيرات ذو أهمية هي: (التعلم النشط، ومهارات التدريس الإبداعي). ب. الحدود المكانية: رياض الأطفال بمنطقة عسير بالمملكة العربية السعودية.

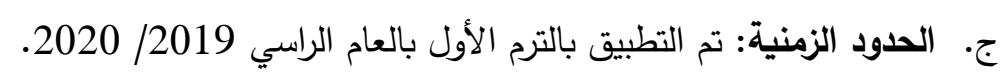
سابعًا - فروض البحث:

1- - يوجد مستوى منخفض من مهارات التدريس الإبداعي لاى معلمات رياض الأطفال في التطبيق القبلي.

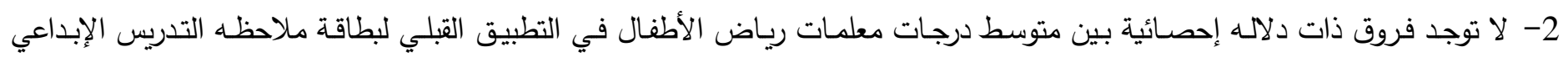
ومتوسط درجاتهم في التطبيق البعدي لبطاقة الملاحظة. 3- يوجد فعالية للبرنامج التدريبي المقترح القائم على استراتيجيات التعلم النشط.

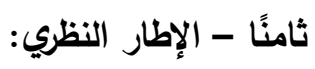
أولا- التعلم النشط: 1 - مفهوم التعلم النشط ولأبطم عرف مايرز وجونز ( Jones \& Myers1993,) التعلم النشط بأنه: "البيئة التعلمية الحرة التي تمنح الطلبة حرية التحدث والإصغاء

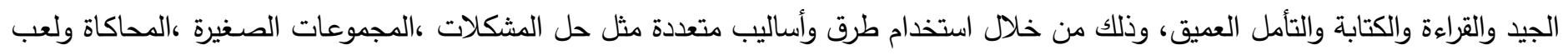

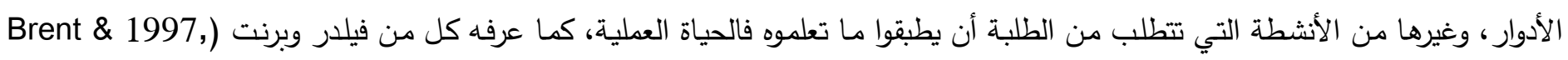
( Felder

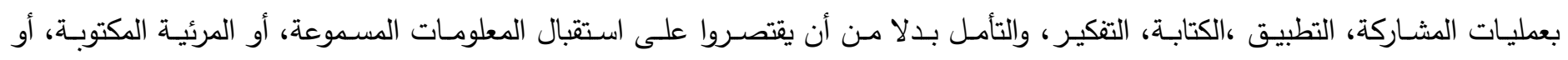
المطبوعة.

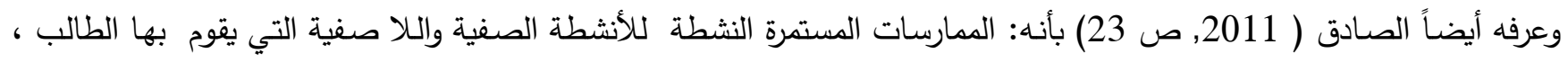
لبناء خبراته معتمداً على نفسه في البحث، والحصول على المعارف، واكتساب المهارات والخبرات تحت إرشاد وتوجيه من المعلم " . 2- 2 أهداف التعلم النشط: يتفق كـلا مـن رفـاعي (2012, ص 63)، زكي، (2012, ص 20)، وكذلك سـعادة (2011, ص 33 :38) وجبـران (2002,ص

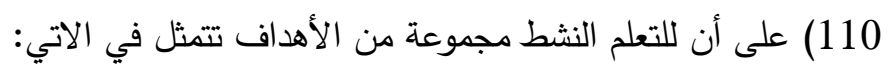
1- تثجع الطلبة على اكتساب مهارات التفكير العليا (التحليل، التركيب، والتقويم) ومهارات حل المشكلات وتمكينهم من تطبيقها في التعلم والحياة. 2-2 - التتوع في الأنشطة التعليمية الملائمة لتحقيق الأهداف التربوية المنشودة. 3- - تثجيع المتعلمين على اكتثاف مهارات التفكير الناقد. 


$$
\begin{aligned}
& \text { 4- - زيادة الأعمال الإبداعية لدى المتعلمين. } \\
& \text { 5- - تشجيع الطلبة على حل المشكلات. } \\
& \text { 6- تحديد كيفية تعلم المتعلمين للمواد الدراسية المختلفة. } \\
& \text { 7- تمكين المتعلمين من اكتساب مهارات التعاون، والتفاعل، والتواصل مع الآخرين. } \\
& \text { 8- دعم الثقة بالنفس لدى المتعلمين نحو ميادين المعرفة المتتوعة. } \\
& \text { 9- - تشجيع المتعلمين على القراءة الناقدة. } \\
& \text { 10- قياس قدرة المتعلمين على بناء الأفكار الجديدة وتتظيمها. } \\
& \text { 11- تثجيع الطلبة على المرور بخبرات تعليميه وحياتيه حقيقية. } \\
& \text { 12- تثجيع الطلبة وتدريبهم على أن يعلموا أنفسهم بأنفسهم. } \\
& \text { ويشير عبد الهادي (2007) إلى أن التعلم النشط يكون أفضل في عدة انس حالات هي: } \\
& \text { 1 - عندما يكون الطالب هو محور العملية التعليمية. } \\
& \text { 2- عندما يراعي قدرات الطالب وسرعة نموه. } \\
& \text { 3 - - عندما يرتبط بحياة المتعلم، وواقعه، واهتماماته، واحتياجاته. }
\end{aligned}
$$

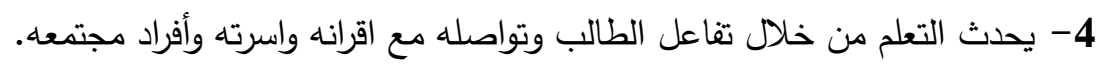

$$
\begin{aligned}
& \text { تعقيب: }
\end{aligned}
$$

ويتضح مما سبق أن جميع أهداف التعلم النشط تعمل على إكساب المتعلم للمعلومة عن طريق المرور بالخبرات المختلفة، وبطرق متتوعة تذهب الملل، وهذا بدوره يساعد على تحفيز المتعلم، وتثجيعه على تعليم نفسه بنفسه تحت إثراف معلمها.

$$
\text { 3- أهمية التعلم النشط: }
$$

يري جبران (2002) إن أهمية التعلم النشط تظهر من النتاجات الأدبية التي يحدثها عند المتعلم، من حيث إكتساب المعرفة، وتتمية

المهارات والاتجاهات لديه، حيث يورد مجموعه من النتائج التي تدل على أهمية التعلم النشط ومن أهمها:

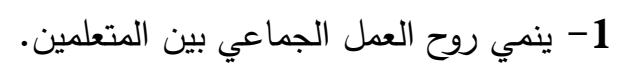$$
\text { 2- ت تمية مهارات التتكير المختلفة. }
$$

3- يدرب المتعلمين على تحمل المسؤولية، والاعتماد على النفس واستدعاء خبراته السابقة.

4- 4

5 - 5 - زيادة تحصيل الطلبة.

6- يتعلم المتعلمين في التعلم النشط عن طريق العمل، وتوظيف المعرفة عن طريق ممارسة ما تعلموه.

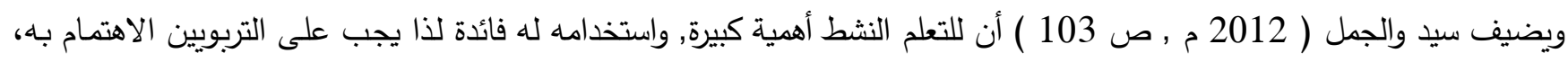

والتشجيع على استخدامه لأنه يساعد على تحقيق ما يلي: 1 1 2- يعطى التعلم النشط صوره واضحة عن الانماط التي يستخدمها التلاميذ في الصف كالاستماع، والفهم، وتحليل المعلومات وتفسيرها،

$$
\text { وتكامل الأفكار • (عويس } 2000 \text { ). }
$$

3- يساعد على تغيير صورة المعلم بأنه المصدر الوحيد للمعرفة. 4- يتعلم التلاميذ في التعلم النشط عن طريق العمل، وتوظيف المعرفة عن طريق ممارسة ما تعلموه. 


$$
\text { 6- 6- يزيد من الرغبة في التفكير والبحث والتعلم حتى الإتقان. }
$$

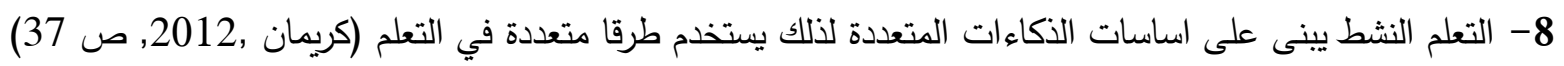
وبعد العرض السابق للتعلم النشط وأهميته بإيجاز وجب علينا إلقاء الضوء على أهم ملامح مهارات التدريس الإبداعية للمعلمين

$$
\text { ثانيا: مهارات التدريس الإبداعي: } 1 \text { - مفهوم التدريس الإبداعي: }
$$

يذكر فلمبان ( 2004،ص 96) أن التدريس الإبداعي هو "مجموعة السلوكيات اللفظية وغير اللفظية التي يظهرها المعلم داخل حجرة الدراسة في أثثاء تفاعله مع الطلاب في الموقف الصفي والتي تعمل على استثارة الإبداع لاى الطلاب ، وتثتمل على الأسئلة الصفية المثيرة

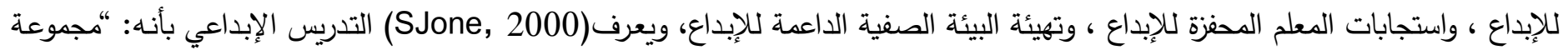
من المبادئ الإرشادية وخطوات التدريس الفعالة التي يظهرها المعلم في نشاطه التعليمي داخل غرفة الصف واتف أو خارجها في شكل التهل استجابات

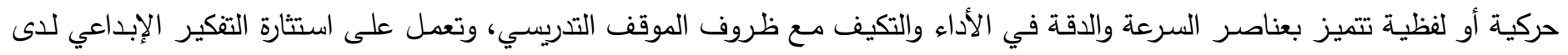
المتعمين وتتميته. كما يُعرف بانه "تدريس فعال يؤكد على التعليم من أجل الفهم العميق كما يؤكد على مهارات الاستقصاء أكثر من تأكيده على إتقان

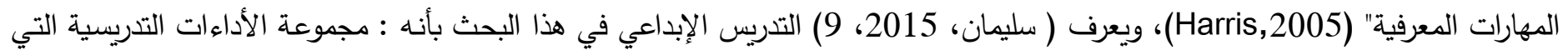

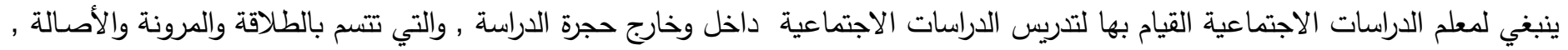
وتساعد في تتمية التفكير الإبداعي والمهارات الحياتية لدي التلاميذ , وتقاس من خلال الاختبار المعرفي وبطاقة الملاحظة التي أعدتها الباحثة

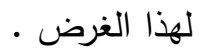
تعرف مهارات التدريس الإبداعي على إنها مجموعة من السلوكيات التي يمتلكها المعلم ، ويتمكن من ممارستها بدقة وإتقان وبسرعة وبأقل مجهود وتكاليف، وذلك أثناء ممارسة معايير التدريس الحقيقي للغة العربية سواء كانت مرتبطة بممارسة معايير مستويات التثكير العليا أو

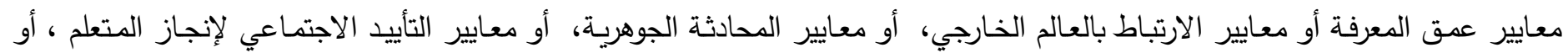

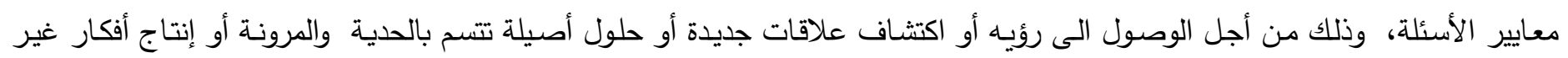

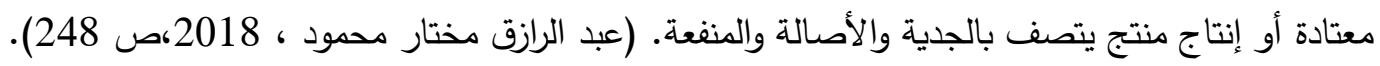

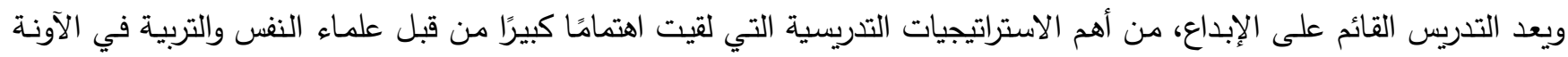

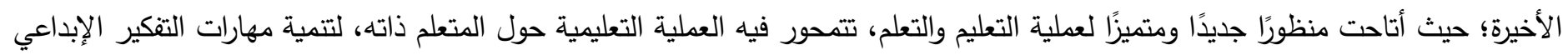

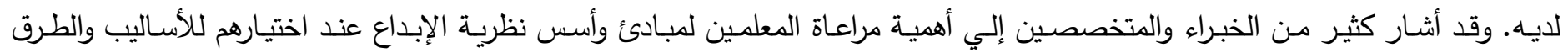

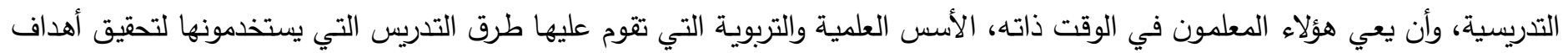
التعليم لدى تلاميذهم، وهذا يستلزم إعادة النظر في المنظومة المعرفية للمنهج وطرق تدريسه وتطويرها بما يتواءم و أنماط التفكير التي يمتلكها

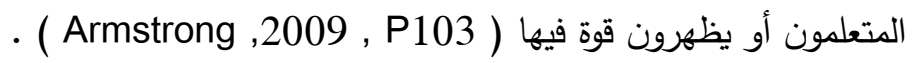
2- مهارات التدريس الإبداعي: تتبثق مهارات التدريس الإبداعي من وافر الإمكانات والظروف الإدارية والفنية والمادية السائدة في المدرسة والتي تشجع على الإبداع، ومن طبيعة المنهج المدرسي، ومن نزعة المعلم الإبداعية. (مختار ,2008, ص 286) يتضمن التدريس الإبداعي سلوكيات ومهارات ضرورية لتحقيق اهدافه من اهمها ما يلي: ومني: 
1- تتمية قدرة الطالب على الانخراط في الأنشطة المختلفة واستقلاليته في التعلم.

2- تثجيع التلاميذ على المناقثة والتعبير عن آرائهر.

3- توفير مواقف تثير التحدي وتثجيع السلوكيات المغايرة البناءة وقبولها.

4- الدعم والتغذية الراجعة لاستقسارات واكتشافات الطلاب.

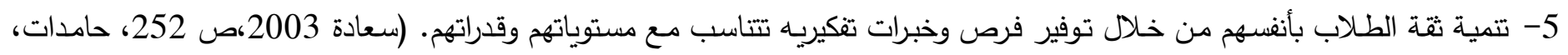

$$
\text { 2009 ، ص 274، ابو جلاله ، 2007). }
$$

وتتظر سناء محمد (2011) إلى مهارات التدريس الإبداعي في ضوء مدى امتلاك المعلم لمهارات التفكير التباعدي او الإبداعي مثل

الطلاقة، المرونة والأصالة والإفاضة والحساسية للمشكلات ويشير كلا من فتحي جراون (1999, ص 82 : 85 :85) وحسن زيتون (2003,ص فركارك 63 65:

1__ الطلاقـة: تعنى القدرة على إنتاج عدد كبير من الأفكار اللفظية او الأدائية او البدائل او المشكلات مفتوحـة النهاية او الاستعمالات او

المترادفات عند الاستجابة لمثير معين والطلاقة هي عملية استدعاء لمعلومات ومفاهيم وخبرات تم تعلمها وتخزينها لدى الفرد.

2__ المرونة: تعنى إنتاج أفكار جديده عن طريق تحويل اتجاه التفكير حسب ما يتطلب الموقف او المثير ، أي رؤية المشكلة او الموقف من زوايا

مختلفة.

3_ الأصـالة: تعد الأصـالة من أكثر المهارات ارتباطا بالإبداع والتفكير الإبداعي وتعنى القدرة على انتاج افكار وحلول ومقترحات جديده غير مألوفة.

ومن هذا المنطلق فإن الاهتمام بالإبداع يعد من أبرز الأولويات وذلك لما له من أثر كبير في تتمية المجتمعات وتقدمها وازدهارها،

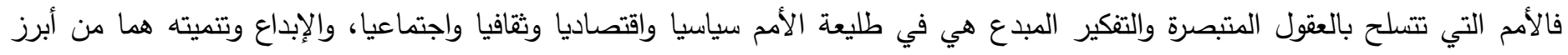

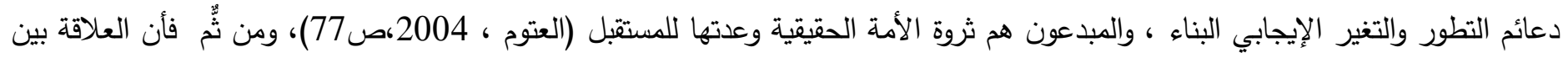

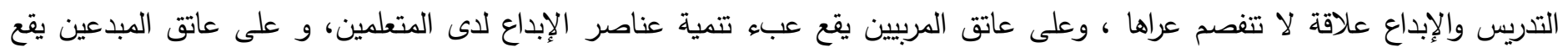

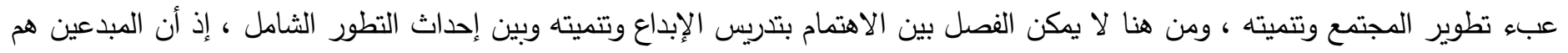

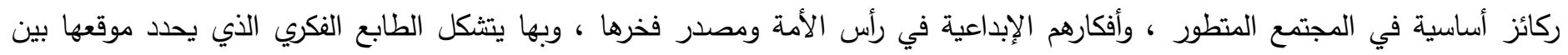

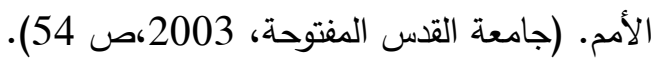
والإبداع بشكل عام ومهارات التدريس الإبداعي بثكل خاص تحتاج إلى مواقف عديدة ومتتوعة، فالموهبة الإبداعية تحتاج بيئة مناسبة

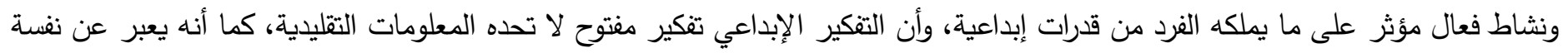

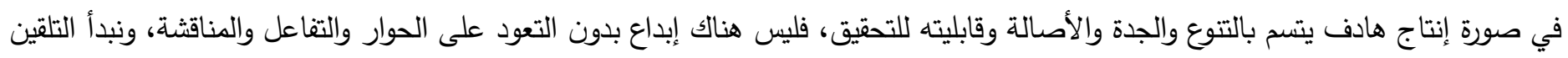

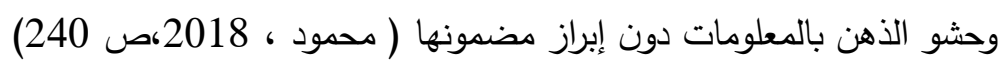
تاسعًا - الدراسات السابقة: 1 1 دراسة (المري، هدفت هذه الدراسة إلى تحديد أثر استخدام استراتيجيات التعلم النشط لتتمية مهارات التدريس الإبداعي لدي معلمي الرياضيات للمرحلة

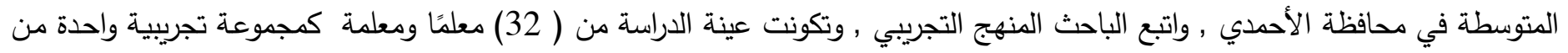
معلمي الرياضيات للمرحلة المتوسطة الذين يعملون في مدارس التعليم العام الحكومي في محافظة الأحمدي وتم اختيارهم بطريقة عشوائية قصدية , وتحددت أداة الدراسة في بطاقة ملاحظة تكونت من (27) فقرة , وتوصلت نتائج الدراسة إلى أن متوسط الأداء التدريسي لأداة بطاقة

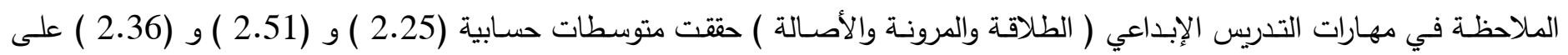


الترتيب , وهذا يدل على توافر هذه المهارات بدرجة ضعيفة , وهي غير كافية , وكثفت نتائج الدراسة عن وجود فرق دال إحصائيًا بين متوسط

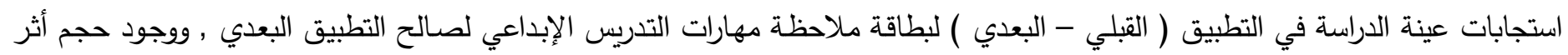
لاستخدام استراتيجيات التعلم النشط على تتمية مهارات التدريس الإبداعي لاى معلمي الرياضيات للمرحلة المتوسطة في محافظة الأحمدي في الكويت بقيمة (0.642).

2018) دراسة محمود (2018)

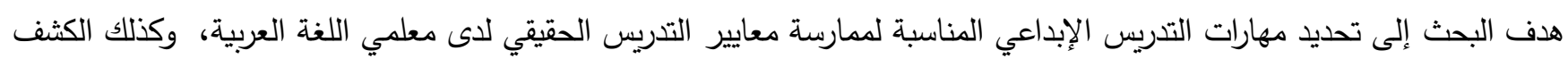

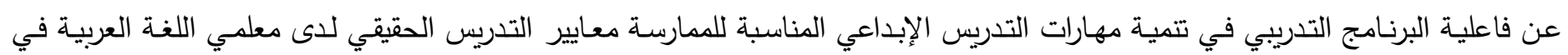
تدريهم ، وقد تم تحديد مجموعة البحث من طلاب الدبلوم المهنية، من المعلمين بلغ عددهم ( 19 ) معلما وقد استخدم البحث الحالي المنهج

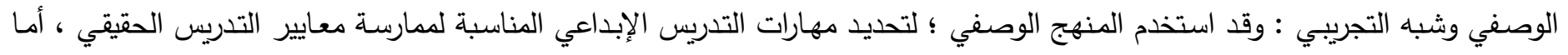
المنهج شبه التجريبي فقد استخدم الوقوف على فاعلية البرنامج التدريبي وقد توصل البحث إلى قائمة بمهارات التدريس الإبداعي المناسبة لممارسة

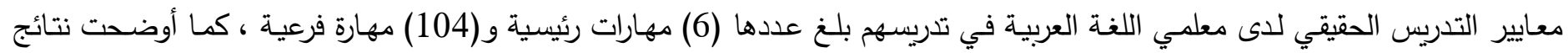
البحث فعالية البرنامج التدريبي في تتمية مهارات التدريس الإبداعي المناسبة لممارسة معايير التدريس الحقيقي لمعلمي اللغة العربية في تدريسهم لتلاميذ الصف الثاني الإعدادي، كما تم تقديم مجموعة من التوصيات والمقترحات في ضوء النتائن النتائج التي توصل إليها البحث.

3- دراسة (تويج , 2017)

وهدف هذا البحث إلي معرفة اثر تدريس اللغة العربية باستخدام استراتيجيات التعلم النشط في تتمية التفكير الإبداعي لدى طلاب الصف السادس الابتدائي بلغت 50 طالب , بواقع 25 طالب للمجموعة التجريبية و25 طالب للمجموعة الضـابطة , وذلك من خـلال تدريس الوحدة الرابعة ( الوعي الصحي ) من منهج لغتي الجميلة للصف السادس , وتم تطبيق اختبار تورانس للتفكير الإبداعي تعريف وتقنين (الثنطي ,

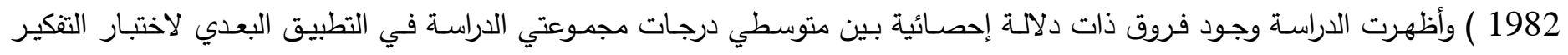
الإبداعي ومهاراته الثلاث , وكان هذا الفرق لصالح المجموعة التجريبية التي درست باستخدام استراتيجيات التعلم النشط .

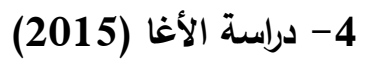

هدفت الدراسة إلى الكثف عن فاعلية برنامج تدريبي لتتمية مهارات التدريس الإبداعي لمعلمي الرياضيات بالمرحلة الثانوية وأثره على التى

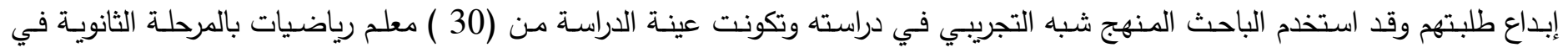
خانيونس، حيث تم تطبيق قبلي للملاحظة عليهم مما تبين ضعف امتلاكهم لمهارات التدريس الإبداعي، وبناء على ذلك فقد قام الباحث بتحديد

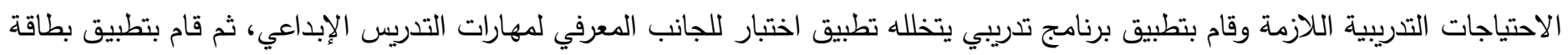
الملاحظة على عينة الدراسة، وقد كان حجم الاثر في التطبيق البعدي كبير مما يدل على فاعلية البرنامج التدريبي.

5- دراسة سليمان (2015)

هدف البحث الحالي إلى التعرف على أثر برنامج تدريبي مقترح لتتمية مهارات التدريس الإبداعي لاىى معلمي الدراسات الاجتماعية

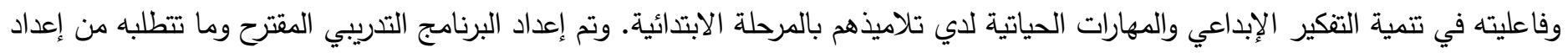
دليل المشارك ودليل المدرب، كما تم إعداد أدوات التقويم والتي تمثلت في: الاختبار التحصيلي، وبطاقة ملاحظة الجانب الأدائي لمهارات

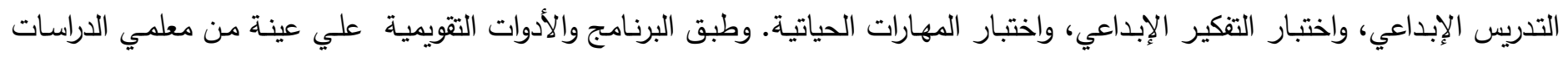

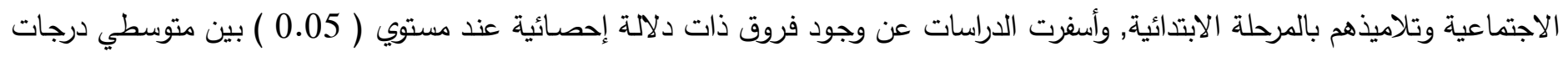
عينة البحث ( من المعلمين ) في القياس القبلي والبعدي لصالح القياس البعدي في التحصيل , والأداء , ووجود فروق ذاتئل ذات دلالة إحصائية عند مستوي ( 0.05 ) بين متوسطي درجات أفراد المجموعة التجريبية وأفراد المجموعة الضابطة ( من التلاميذ ) في القياس البعدي , في التفكير 
الإبداعي وفي المهارات الحياتية , لصالح أفراد المجموعة التجريبية ـ ويوصي البحث بتطوير برامج إعداد المعلم بكليات التربية، بما يكفل اكتساب الطالب المعلم لمهارات التدريس الإبداعي، وبما يساعدهم في تتمية مهارات التفكير الإبداعي والمهارات الحياتية لدى تلاميذهم.

6- دراسة الأستاذ (2013)

هدفت الدراسة إلى الكثف عن فاعلية التعلم التعاوني في تتمية مهارات التنكير الناقد في تدريس الجغرافيا لاى طلبة الصف العاشر، التهاد

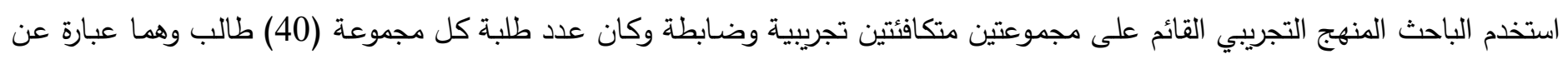
صفين عاشر في مدرسة شمال غزة، وتم تطبيق اختبار قبلي وبعدي، وقد توصلت الدراسة إلى وجود فروق ذات دلالة إحصائية بين متوسط التيط درجات المجموعتين في التطبيق البعدي لصالح المجموعة التجريبية.

7- دراسة العالول (2012)

هدفت الدراسة إلى معرفة أثر توظيف بعض استراتيجيات التعلم النشط "مسرحة المنهج، الألعاب التعليمية، التعلم التعاوني" في تتمية

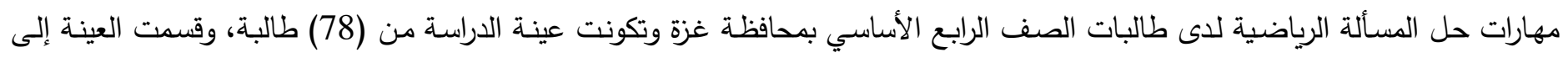
مجموعتين ضابطة وتجريبية، واستخدمت الباحثة تحليل المحتوى واختبار تحصيلي لمهارات حل المسألة الرياضية وتوصلت الدراسة إلى وجود

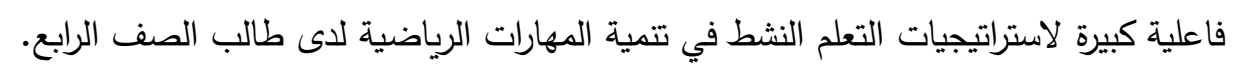

8- دراسة حلس (2011)

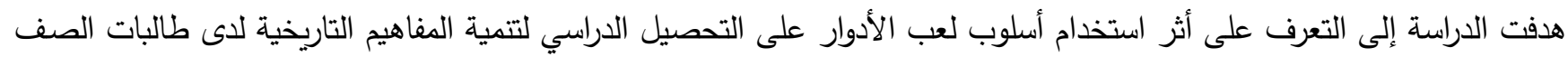

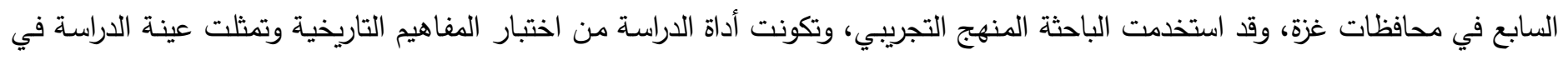
(172) طالبة توزعت على أربعة فصول تم اختيارها بطريقة قصدية، وقد توصلت النتائج إلى وجود فروق ذات دلالة إحصائية بين متوسطي درجات المجموعتين التجريبية والضابطة في اختبار المفاهيم التاريخية لصالح المجموعة التجريبية.

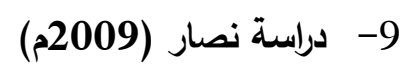
هدفت الدراسة إلى التعرف على أثر استخدام الألغاز في تتمية التفكير الناقد في الرياضيات والميل نحوها لدى طلبة الصف الرابع

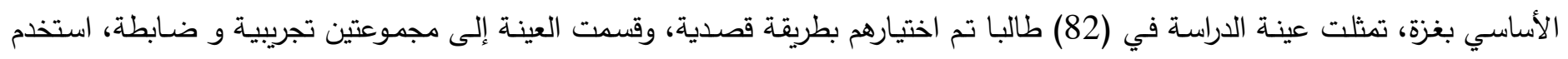
الباحث المنهج التجريبي وتمثلت أدوات الدراسة في اختبار قياس مهارات التفكير الناقد، ومقياس الميل نحو الرياضيات وقد وقد أظهرت النتائج وجود

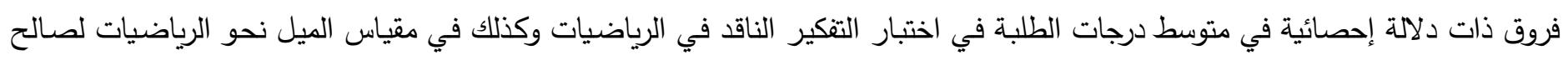

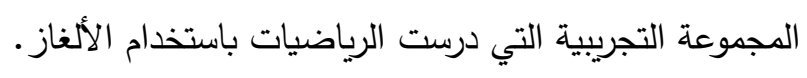

10 10

هدفت هذه الدراسة إلى معرفة فاعلية استخدام استراتيجية التعليم التعاوني في تحصيل طالبات الصف السابع الأساسي في الرياضيات

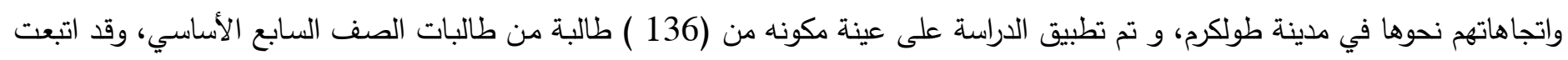
المنهج التجريبي وتم تقسيم العينة في مدرستين في كل مدرسة مجموعة تجريبية وضابطة، وقد تم تطبيق اختبار تحصيلي ومقياس اتجاه قبلي التي

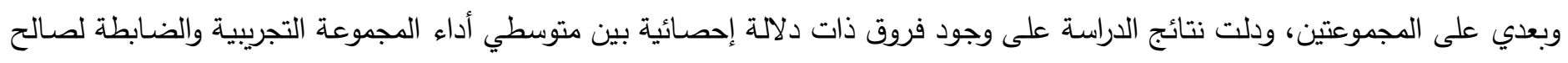
طالبات المجموعة التجريبية وكذلك كان مقياس الاتجاه نحو الرياضيات لصالح المجموعة لتردية لتجريبيه.

(2001) 11 دراسة وينج

هدفت الدراسة إلى معرفة أثر ممارسة طريقة التدريس الإبداعي في تدريس العلوم على هيئة منهج دراسي علمي بالمرحلة الابتدائية في

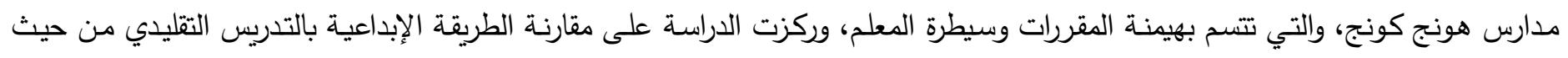

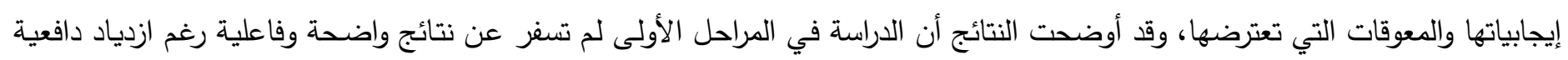


الطلبة نحو التعليم، كما أسهمت في جعل عملية التعليم أكثر اتزاناً وفهما ومن خلال ممارسة المعلمين للتدريس الإبداعي والتدريب على مهارات التفكير العليا وجد الباحث نتيجة إيجابية تثير إلى تقليص معدل الانحراف في أداء التعلم لدى الطلبة على الرغم من عدم وجود دلالمة على تقدم

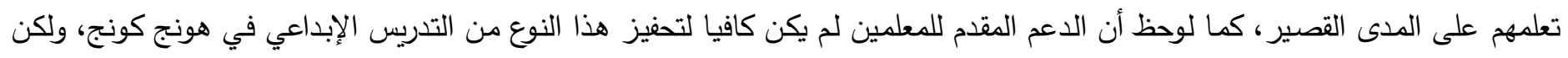

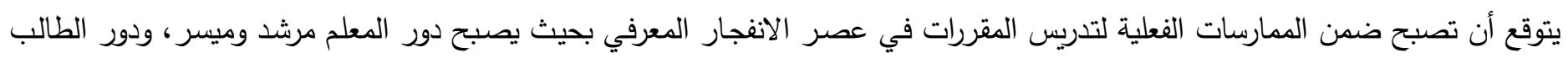
مستكثف في العملية الإبداعية.

-10

هدفت هذه الدراسة إلى معرفة فاعلية برنامج مقترح لإكساب الطلبة المعلمين تخصص رياضيات مهارات التدريس الإبداعي ،وطبقت الدراسة على عينة عشوائية من الطلبة المعلمين تخصص رياضيات في المستوى الثامن بكلية المعلمين بالطائف عددهم (21) طالبا ، واستخدم

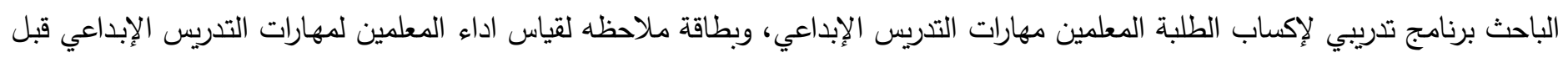
تنفيذ البرنامج وبعده وقد اظهرت النتائج فاعلية برنامج البرنامج المقترح في تتمية مهارات التدريس الإبداعي لدى أفراد عينة الدراسة من الطلبة - المعلمين التعقيب على الاراسات السابقة: 1. اتفت هذه الدراسة مع بعض الدراسات السابقة في اعتمادها على استراتيجيات التعلم النشط في بناء البرنامج التدريبي مثل دراسة الاستاذ (2013) ودراسة العالول (2012).

2. اختلفت هذه الدراسة بعض الدراسات السابقة في الاستراتيجيات الخاصة بالتعلم النشط التي تبنتها الدراسة حيث تبنت الدراسة استراتيجيات خاصه بالتعلم النشط (استراتيجية العصف الذهني، استراتيجية التعلم الذاتي، واستراتيجية تعلم الأقران)

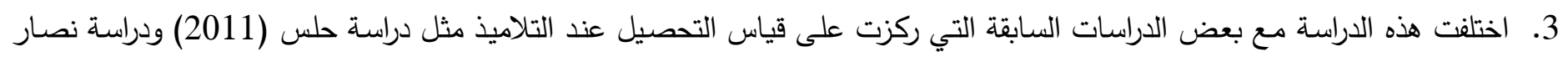
(2009) ودراسات يحيى (2009)، حيث ركزت هذه الدراسة على تدريب معلمات رياض الأطفال حيث أن المعلمة تعتبر ركيزة اساسيه في عمليه التعلم بالنسبة للأطفال.

4- اتفتت هذه الدراسة مع بعض الدراسات السابقة في إعداد برنامج تدريبي من اجل تتميه التدريس الإبداعي مثلا دراسة الأغا (2015) دراسة فلمبان (2004)

5- اتفقت هذه الدراسة مع بعض الدراسات السابقة باتباع المنهج التجريبي بمجموعه واحده مثل دراسة (الأغا، 2015) ودراسة (2001, wing) ومن أوجه الاستفادة من الاراسات السابقة 1- الإمام بموضوع الدراسة والتركيز عليه وبناء الإطار النظري. 2- اختيار عينة الدراسة الحالية. 3- تعريف مصطلحات الدراسة. 4- عرض نتائج الدراسة ومناقثتها وتتديم التوصيات والمقترحات. عاشرًا - الإجراءات الميدانية للبحث: 1- المنهج المستخدم: استخدت الباحثة المنهج شبه التجريبي والمنهج الوصفي: شبه التجريبي من خلال البحث عن فعالية برنامج مقترح قائم

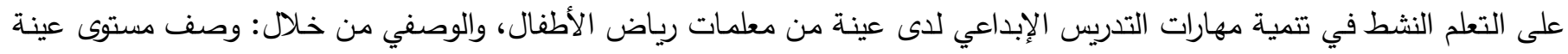
البحث في متغير مهارات التدريس الإبداعي في التطبيق القبلي. 2- مجتمع البحث: معلمات رياض الأطفال بمنطقة عسير بالمملكة العربية السعودية. 
3- عينة البحث: تم أخد عينة البحث بالطريقة العشوائية، وبلغت عينة البحث الحالي (90) معلمه من معلمات رياض الأطفال بمنطقة عسير

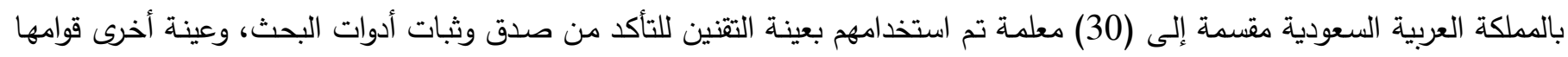

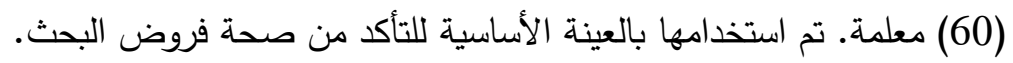
4- أدوات البحث:

أولا- قائمة ملاحظة مهارات التدريس الإبداعية لمعلمات رياض الأطفال (إعداد الباحثة /2020).

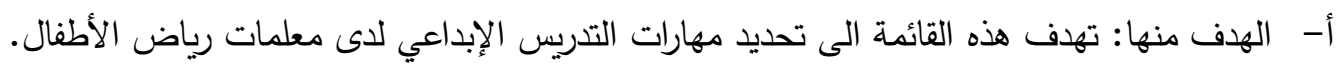
ب- وصف القائمة: تقيس هذه القائمة مهارات التدريس الإبداعي للى معلمات رياض الأطفال، من خلال قائمة ملاحظه التدريس الإبداعي لاى معلمات

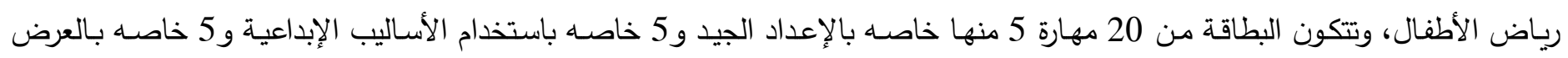
المشوق و5 خاصه بالتقويم ج- طريقة تصحيح القائمة: تم تحديد أسلوب التقدير الكمي للقائمة، من خلال مقياس ليكرت ثلاثي: ممتاز تحصل المعلمة على ثلاث درجات، جيد جدا تحصل المعلمة على درجتان، جيد تحصل المعلمة على درجه واحده. وتتراوح الدرجات من (20 :60) وتدل الدرجة المنخفضة الى الافتقار لمهارات التدريس الإبداعي والدرجة المرتفع إلى التمتع بهارات التدريس الإبداعي. د- الشروط السيكومتربية للقائمة.

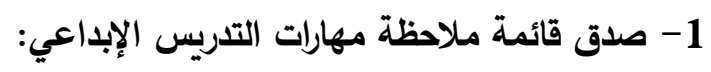

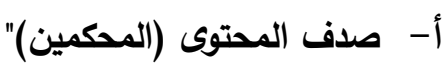
تم عرض هذه القائمة على مجموعه من المتخصصين في مجال رياض الأطفال ومجموعه من معلمات رياض الأطفال المشهود لهم بالكفاءة، وعددهم (9) وذلك من أجل الوصول إلى القائمة في صورتها النهائية وقد أخذت الباحثة جميع اراء المحكمين حول المهارات التي يجب التبات

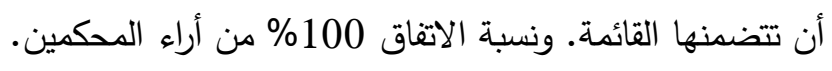
1 - صدق الاتساق الداخلي: قامت الباحثة بالتحقق من صدق الاتسات لاقتاق الداخلي من خلال تطبيق قائمة ملاحظة مهارات التدريس الإبداعي على عينة استطلاعية من

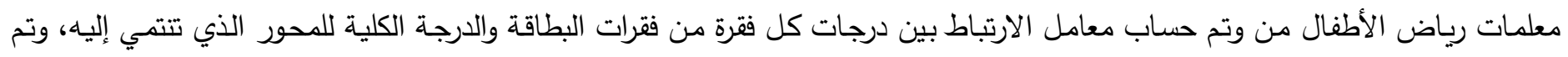

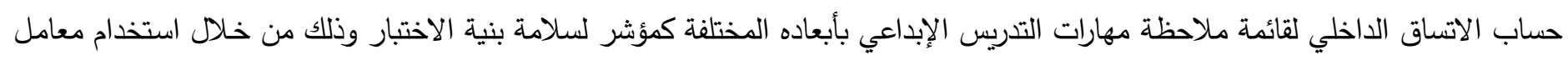

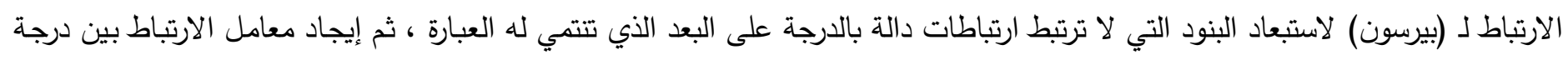

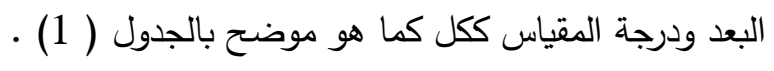
أ- أيجاد معامل الارتباط بين درجة المفردات ودرجة البعد التي تنتمي إليه.: جدول (1) معاملات الارتباط بين درجة المفردة ودرجة البعد التي تنتمي إليه عند ن = 50

\begin{tabular}{|c|c|c|c|c|c|}
\hline معامل الارتباط بالبعد & اسم البعد & رقم البند & معامل الارتباط بالبعد & اسم البعد & رقم البند \\
\hline$* 0,419$ & \multirow{5}{*}{ 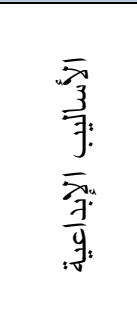 } & 6 & $* * 0,494$ & \multirow{5}{*}{$\begin{array}{l}\overline{\bar{y}_{a}} \\
\frac{\bar{y}}{7} \\
\overline{\bar{y}}\end{array}$} & 1 \\
\hline$* * 0,526$ & & 7 & $* * 0,513$ & & 2 \\
\hline * 0,381 & & 8 & $* * 0,488$ & & 3 \\
\hline$* * 0,513$ & & 9 & $* 0,440$ & & 4 \\
\hline$* 0,437$ & & 10 & $* * 0,454$ & & 5 \\
\hline
\end{tabular}




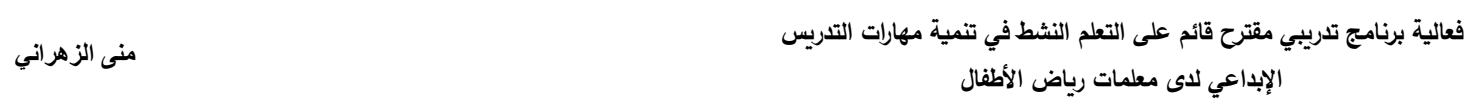

\begin{tabular}{|c|c|c|c|c|c|}
\hline$* 0,444$ & \multirow{5}{*}{ 電 } & 16 & $* 0,418$ & \multirow{5}{*}{ 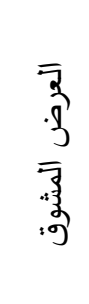 } & 11 \\
\hline$* 0,379$ & & 17 & $* 0,415$ & & 12 \\
\hline$* 0,443$ & & 18 & $* * 0,489$ & & 13 \\
\hline$* * 0,499$ & & 19 & $* 0,421$ & & 14 \\
\hline$* * 0,520$ & & 20 & $* * 0,505$ & & 15 \\
\hline
\end{tabular}

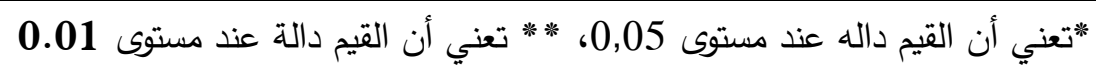

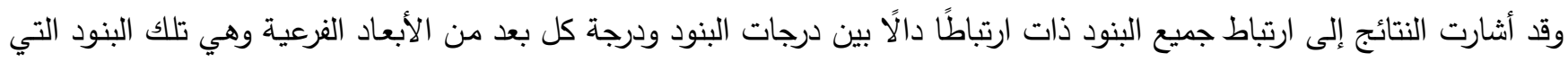

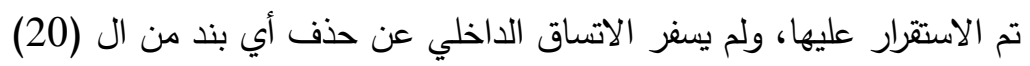

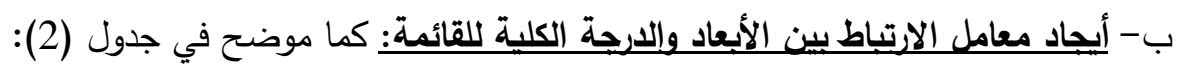

\begin{tabular}{|c|c|c|}
\hline الارتباط بالدرجة الكلية للمقياس & الأبعاد الفرعية للمقياس & b \\
\hline$* * 0,800$ & الإعداد الجيد & 1 \\
\hline$* * 0,701$ & الأساليب الإبداعية & 2 \\
\hline *** 0,738 & العرض المشوق & 3 \\
\hline$* * 0,768$ & التقويم & 4 \\
\hline
\end{tabular}
جدول (2) معاملات الارتباط بين درجة الأبعاد الفرعية والدرجة الكلية للقائمة

ومن الجدول السابق تم التوصل إلى ارتباطات دالة بين كل بعد من أبعاد المقياس والدرجة الكلية للمقياس وجميعها دالة عند مستوى (0,01)، ومن ثم تشير هذه النتائج إلى تمتع القائمة بقدر كبير من التجانس الداخلي للعبارات دات والأبعاد. 2- ثبات القائمة: تم حساب ثبات قائمة مهارات التدريس الإبداعية عن طريق معامل ثبات الفاكرونباخ لأبعاد المقياس والدرجة الكلية للمقياس حيث جاءت كما هو موضح في جدول (3) كالتالي:

\begin{tabular}{|c|c|c|c|}
\hline معامل الفا كرونباخ & عدد العبارات & الأبعاد الفرعية للمقياس & s \\
\hline 0,621 & 5 & الإعداد الجيد & 1 \\
\hline 0,652 & 5 & الأساليب الإبداعية & 2 \\
\hline 0,689 & 5 & العرض المشوق & 3 \\
\hline 0,667 & 5 & التقويم & 4 \\
\hline 0,741 & 20 & مهارات التدريس الإبداعي ككل & \\
\hline
\end{tabular}

جدول (3) معاملات الثبات لمقياس مهارات التدريس الإبداعية بأبعاده المختلفة.

ويتبين من الجدول (3) أن جميع معاملات ثبات الأبعاد والقائمة ككل جيدة، مما يثير أن المقياس يتمتع بدرجة جيدة من الثبات. ثانيًا- البرنامج المستخدم 1 يعتمد البرنامج على مجموعه من الاسس لئسئ _ـتوظيف استراتيجيات التعلم النشط ووسائل تتميه مهارات التدريس الإبداعي لدى معلمات رياض الأطفال. _مراعاة الفروق الفردية بين المتدربين.

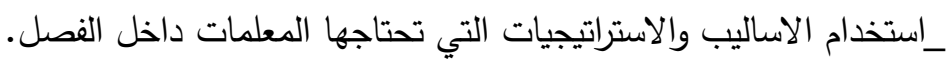


_التقويم الثامل (تقويم قبلي، تقويم اثناء تتفيذ البرنامج، تقويم بعدى).

2- 2 - 2 - الهدف من البرنامج:

إتقان معلمات رياض الأطفال لمهارات التدريس الإبداعي بالاستعانة باستراتيجيات التعلم النشط.

3- بناء محتوى البرنامج:

تم بناء محتوى البرنامج من خلال: 1-الاطلاع على الادبيات السابقة التي تتاولت التعلم النشط والتدريس الإبداعي.

2-تحديد الموضوعات الخاصة باستراتيجيات التعلم النشط ومهارات التدريس الإبداعي وتم تقسيمها على جلسات تدريبيه. 3-إعداد المحتوى العلمي لكل جلسة بما يتتاسب مع معلمات رياض الأطفال وقد يحتوي البرنامج على مجموعه من المحاضرات النظرية وكذلك التطبيق العملي لتلك المحاضرات. 4 4- تم تقسيم البرنامج على (8) لقاءات كل لقاء (4) ساعات. 4-استراتيجيات تنفيذ البرنامج:

اعتمدت الباحثة في البرنامج على استراتيجيات التعلم النثط وهي استراتيجية (العصف الذهني، استراتيجية التعلم الذاتي واستراتيجية تعلم الأقران) وتم استخدام العديد من الوسائل التي تساعد في التدريب على استخدام السبورة وشاشات العرض الضونئي. 5- أساليب التقويم:

1-التقويم التكويني يتم تقويم اداء المعلم اثثاء البرنامج التدريبي من خلال اوراق العمل الجماعي والمشاركة في الأنشطة.

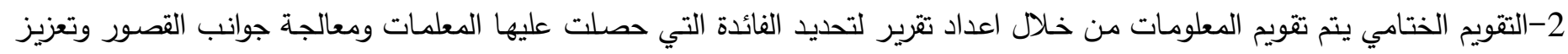
جوانب القوة لدى المعلمات وتم تكوين مدى الرضا عن المعلومات عن محتوى التدريب وتم تطبيق بطاقة ملاحظة الاداء التدريسي التي أعدتها الباحثة من اجل الدراسة وذلك لقياس مهارات التدريس الإبداعي عند المعلمات.

6 - ضبط البرنامج المقترح: تم عرض البرنامج على مجموعه من المحكمين وذلك من اجل الحكم على مدى صلاحيتها للتطبيق وقد راعت الباحثة آراء المحكمين والتي كان لها دور فعال في تعديل البرنامج ليصبح قابل للتطبيق.

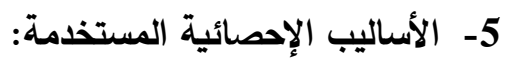

1. لاختبار صحة الفرض القائل ب " يوجد مستوى منخفض من مهارات التدريس الإبداعي لدى معلمات رياض الأطفال في التطبيق القبلي لبطاقة

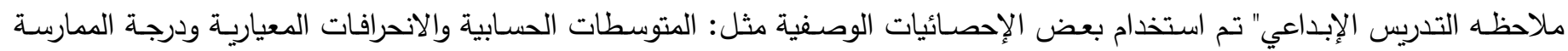
والأوزان النسبية والترتيب.

2. لاختبار صحة الفرض القائل: لا توجد فروق ذات دلاله إحصـائية بين متوسط درجات معلمات رياض الأطفال في التطبيق القبلي لقائمـة

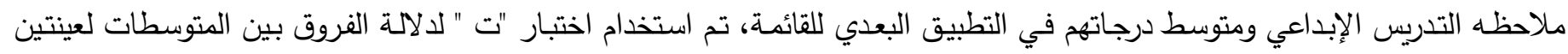
مترابطتين. 3. لاختبار صحة الفرض القائل ب: لا يوجد فعالية للبرنامج التدريبي المقترح القائم على استراتيجيات التعلم النثط في تتمية مهارات التدريس

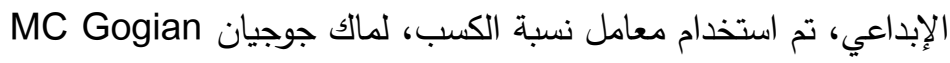

الحادي عشر - عرض النتائج ومناقشتها: نتائج الفرض الأول ومناقشتها: 
والذي ينص على " يوجد مستوى منخفض من مهارات التدريس الإبداعي للى معلمات رياض الأطفال في التطبيق القبلي لبطاقة ملاحظه التدريس الإبداعي.

ولاختبار صـحة هذا الفرض تم حسـاب المتوسط الحسـبي والانحراف المعياري والاوزان النسبية ودرجـه الممارسة لمهارات التدريس الإبداعي لدرجات عينه الدراسـة على بطاقة ملاحظة التدريس الإبداعي للى معلمات رياض الأطفال وكذلك كل مهاره من مهارات التدريس الإبداعي وتم ترتيب هذه المهارات حسب الأوزان النسبية لها، والجدول التالي يوضح المتوسطات الحسابية والانحرافات المعيارية ودرجه الممارسة

والاوزان النسبية والترتيب لكل مهاره من مهارات التدريس الإبداعي حسب عيدات عينه المعلمات. جدول رقم (4) المتوسطات الحسابية والانحرافات المعيارية ودرجة الممارسة والاوزان النسبية والترتيب لكل مهاره من مهارات التدريس

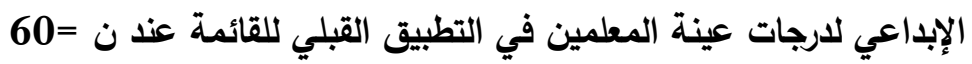

\begin{tabular}{|c|c|c|c|c|c|}
\hline الترتيب & المستوى & شدة متوسط الاستجابة & الافتراضي & المستوسط & المهارة \\
\hline 1 & متوسط & $\% 51,00$ & 10 & 7,65 & الإعداد الجيد \\
\hline 2 & متوسط & $\% 50,20$ & 10 & 7.54 & العرض المشوق \\
\hline 4 & منخفض & $\% 35,60$ & 10 & 5.34 & استخدام الأساليب الإبداعية \\
\hline 3 & منخفض & $\% 42,86$ & 10 & 6,43 & التقويم \\
\hline \multicolumn{2}{|c|}{ منخفض } & $\% 44,93$ & 40 & 26.96 & البطاقة ككل \\
\hline
\end{tabular}

يتضح من الجدول السابق أن 1. ممارسات معلمات رياض الأطفال لمهارات التدريس الإبداعي جاءت متوسطة في بعدين هما (الإعداد الجيد، والعرض المشوق) بينما جاءت منخفضة في بعدين هما (الأساليب الإبداعية، والتقويم) وجاءت المهارات التدريسية الإبداعية ككل بدرجة منخفضئة ويمكن تفسير هذه النتائج بالآتي:

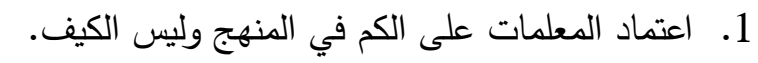
2. ضعف تدريب المعلمات على مهارات التدريس الإبداعي. 3. عدم حضور المعلمين للدورات التدريبية الخاصة بالإبداع.

4. كما تؤكد هذه النتيجة ضعف الممارسات التدريسية الإبداعية لدي معلمات رياض الأطفال.

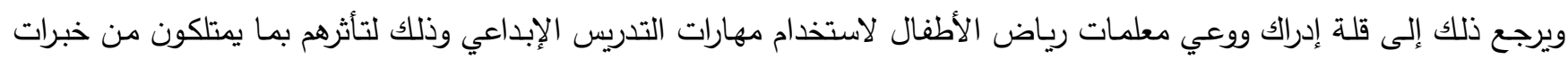
سابقة وتغذية راجعة خلال ممارستهم التدريسية، وذلك لأنهم تعودوا في تدريس لمرحلة رياض الأطفال على طرائق التدريس التقليدية الروتينية ,

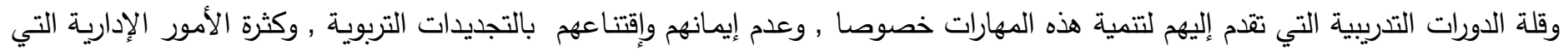
تقع على عاتقهم من قبل إدارة المدرسة وانشغالهم بها مما يؤثر على إبداعهم في ميدان التدريس , وكذلك القصور الواضـح من قبل الجهات

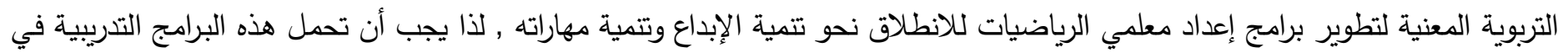
طياتها عن أهمية المعلم وتحفيزه وتثجيعه على الابتكار والأبداع •

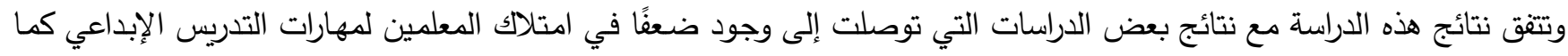

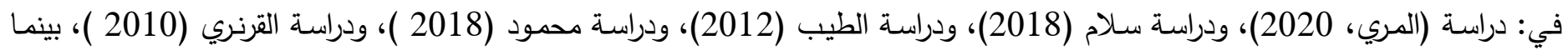
اختلفت هذه النتيجة مـع دراسة فروسارد وآخرون (2012 ) التي أسفرت على أن هناك تقدما ملحوظا في استخدام المعلمين لمهارات التدريس 
مناقشة نتائج التساؤل الثاني:

والذي ينص على " لا توجد فروق ذات دلاله إحصائية بين متوسط درجات معلمات رياض الأطفال في التطبيق القبلي لبطاقة ملاحظه

التدريس الإبداعي ومتوسط درجاتهم في التطبيق البعدي للبطاقة؟ للإجابة على هذا التساؤل واختبار الفرضية المرتبط بـه قام الباحث بتطبيق بطاقة ملاحظه مهارات التدريس الإبداعي للى معلمات رياض الأطفال وتم حساب المتوسط الحسابي والانحراف المعياري وكذلك قيمه (ت) للمقارنة بين متوسطات المجموعتين متربطتين. جدول رقم (5): دلالة الفروق بين القياس القبلي والقياس البعدي لمجموعة بيانات البطاقة عند ن =60 كتورئ

\begin{tabular}{|c|c|c|c|c|c|}
\hline مستوي & قيمة ت & الانحراف المعياري & المتوسط الحسابي & مجموعة الدراسة & المتغير التابع \\
\hline \multirow{2}{*}{0.000} & \multirow{2}{*}{-22.989 ** } & 0.23647 & 7,65 & القبلي & \multirow{2}{*}{ الإعداد الجيد } \\
\hline & & 0.25234 & 13.23 & البعدي & \\
\hline \multirow{2}{*}{0.000} & \multirow{2}{*}{$-25.685^{* *}$} & 0.21942 & 7.54 & القبلي & \multirow{2}{*}{ العرض المشوق } \\
\hline & & 0.23338 & 14,45 & البعدي & \\
\hline \multirow{2}{*}{0.000} & \multirow{2}{*}{$-19.325^{* *}$} & 0.27786 & 5.34 & القبلي & \multirow{2}{*}{ استخدام الأساليب } \\
\hline & & 0.27297 & 11,34 & البعدي & \\
\hline \multirow{2}{*}{0.000} & \multirow{2}{*}{$-23.241^{* * *}$} & 0.23840 & 6,43 & القبلي & \multirow{2}{*}{ التقويم } \\
\hline & & 0.23840 & 12,11 & البعدي & \\
\hline \multirow{2}{*}{0.000} & \multirow{2}{*}{-42.241 ** } & 7.23840 & 26.96 & القبلي & \multirow{2}{*}{ الإبداعي ككل التدريس } \\
\hline & & 5.44840 & 51.13 & البعدي & \\
\hline
\end{tabular}

0,01 تعنى أن قيمة ت داله عند مستوى *

يوضح الجدول السابق:

وجود فروق ذات دلاله إحصائية بين متوسط درجات معلمات رياض الأطفال في التطبيق القبلي لبطاقة ملاحظه التدريس الإبداعي ومتوسط درجاتهم في التطبيق البعدي للبطاقة لصالح التطبيق البعدي. وهذا يدل على وجود فروق في القياس القبلي والبعدي ويشير ذلك على عدم قبول الفرض العدم القائل لا توجد فروق ذات دلالة

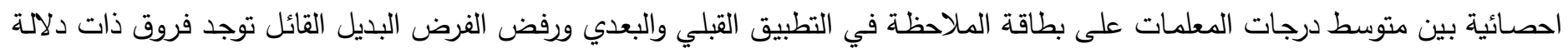
إحصائية بين متوسط درجات معلمات رياض الأطفال في التطبيق القبلي لبطاقة ملاحظه التدريس الإبداعي ومتوسط درجاتهم في التطبيق البعدي ولئي للبطاقة لصالح التطبيق البعديُّ. يمكن تفسير النتائج من خلال الاتي: 1. نجاح البرنامج في استخدام استراتيجيات التعلم النشط التي ساعدت في سهوله تعلم المعلمات لمهارات التدريس الإبداعي. 2.

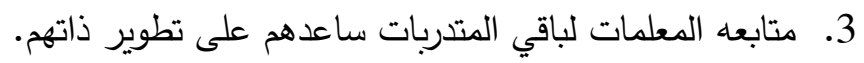

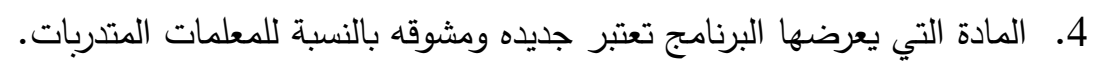
وترجع الباحثة هذه النتيجة إلى تدريب معلمات رياض الأطفال من خلال التركيز علي المهارات العقلية وعدم الاقتصار علي مهارات الحفظ والتلقين , وإثعار المعلمين بالألفة والمحبة والتعاون لزيادة قدرتهم على التوليف بين الدعلى التومات والأفكار للوصول إلى ما هو أصيل وتوليد العديد من الأفكار والحلول , مما قد يسهم بشكل فعال في زيادة إنتاجيتهج في مهارات التدريس الإبداعي , وقد يرجع ذلك إلى اهتمام دليل المعلم 


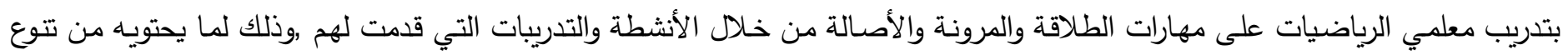

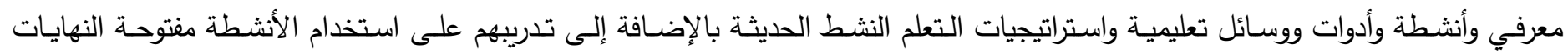

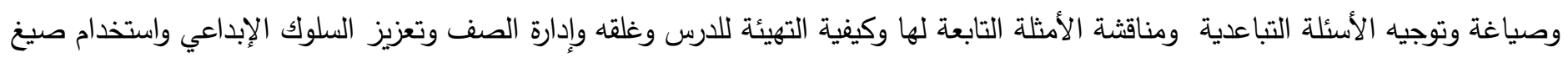

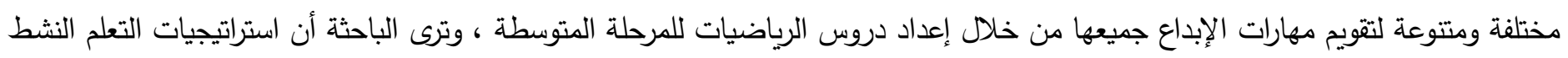

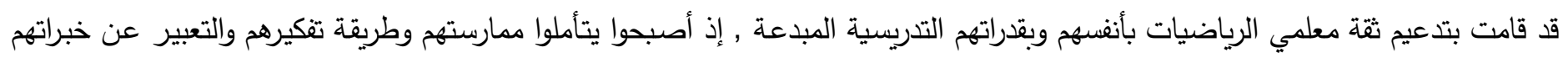

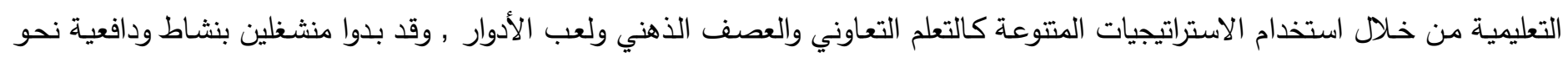

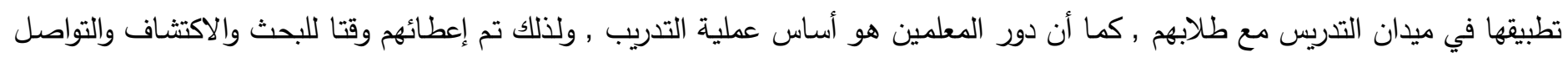

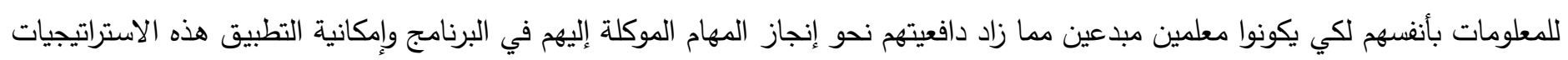

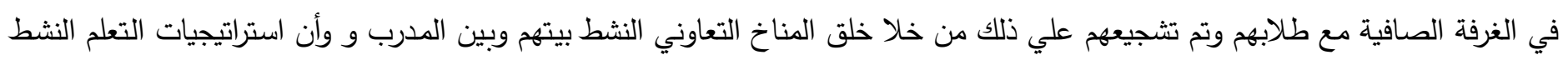
ساعدت علي جعل الطالب محورا للعملية التعليمية لكي يكتشف المعلومة والمفاهيم والتعميمات والنظريات التي اكتشفها بنفسه لديه . واتفتت هذه النتيجة مع: دراسة القرني ( 2010 )، ودراسة الأغا والآخرون ( 2014 ) )، ودراسة السويجي ( 2015 ) ), ودراسة الجمل (

$$
2019 \text { ) , ودراسة ( المري ، 2020). }
$$

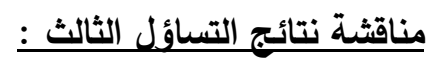
والذي ينص على " توجد فعالية للبرنامج التدريبي المقترح القائم على إستراتيجيات التعلم النشط في تتمية مهارات التدريس الإبداعي لاى عينة من

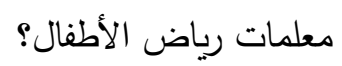
وللإجابة عن هذا السؤال واختبار صحة الفرضية المرتبطة به قامت الباحثة بتطبيق بطاقة ملاحظة مهارات التدريس الإبداعي لدى

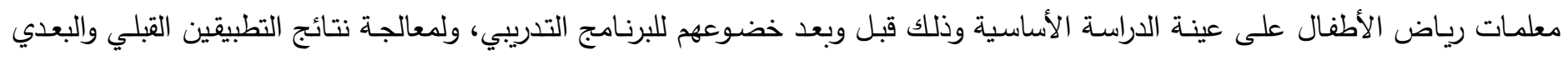

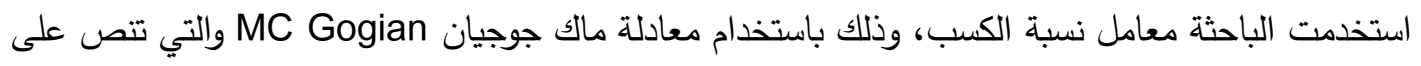

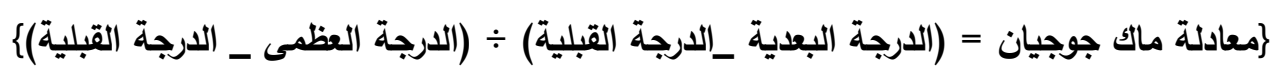

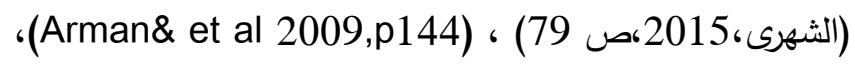
يوضـح الجدول التالي متوسط درجات معلمات رياض الأطفال أفراد العينة الأساسية للدراسة في التطبيق القبلي، ومتوسط درجاتهم في كي التطبيق البعدي لبطاقة ملاحظة مهارات التدريس الإبداعي وذلك في البطاقة ككل وفى كل بعد من ابعادها الأربعة، كما يوضـح الجدول كذلك فئك

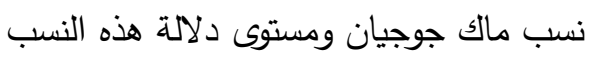
جدول رقم (6): متوسطات درجات المعلمات في التطبيق القبلي والبعدي لقائمة التدريس الإبداعي ونسب ماك جوجيان

\begin{tabular}{|c|c|c|c|c|}
\hline معدل الكسب لماك جوجيان & متوسط درجات التطبيق & متوسط التطبيق القبلي & النهاية العظى للدرجات & 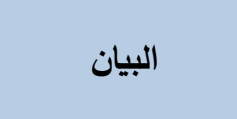 \\
\hline 0.825 & 13.23 & 7,65 & 15 & الإعداد الجيد \\
\hline 0.926 & 14,45 & 7.54 & 15 & العرض المشوق \\
\hline 0.621 & 11,34 & 5.34 & 15 & الأساليب الإبداعية \\
\hline 0.662 & 12,11 & 6,43 & 15 & التقويم \\
\hline 0.749 & 51.13 & 26.96 & 60 & البطاقة ككل \\
\hline
\end{tabular}

ويتضح من الجدول السابق وجود فعالية للبرنامج المقترح في تتمية مهارات التدريس الإبداعي بأبعادها المختلفة (الإعداد الجيد، العرض

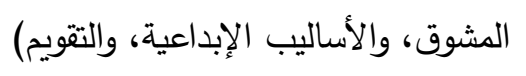


1. مراعاة للفروق الفردية للمعلمات المشتركات.

2. تبادل الخبرات التربوية بين المعلمات أثثاء التدريب.

3. تزويد المعلمين في المصادر والمراجع المتتوعة للبحث والاطلاع.

4. تزويد المعلمات بالاستراتيجيات الخاصة بالتعلم النشط من اجل تطبيقها داخل الفصل.

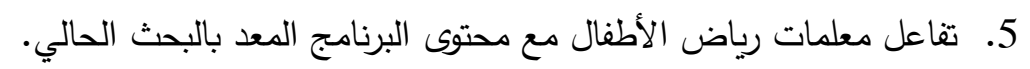

$$
\text { الثاني عشر - توصيات البحث: }
$$

من خلال نتائج الدراسة توصي الباحثة بالآتي:

1. تشجيع معلمات رياض الأطفال على الاهتمام بالدورات التربوية.

2. توفير المتطلبات التي تساعد المعلمات على تطبيق مهارات التدريس الإبداعي.

3. الاستفادة من البرنامج من خلال اعادة تطبيقه على مجموعه أكبر من المعلمات.

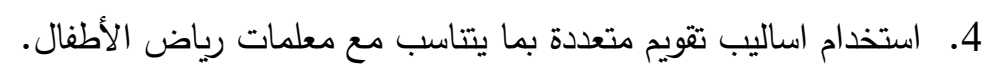

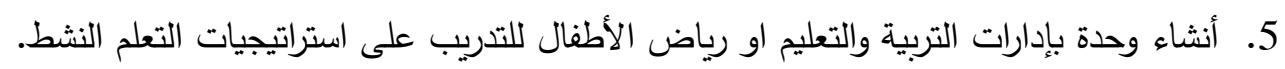

6. تتفيذ دورات تدريبية لمهارات التدريس الإبداعي لمعلمات رياض التئد الأطفال.

الثالث عشر - البحوث المقترحة:

1. إجراء دراسات مماثله لتتميه مهارات التدريس الإبداعي وذلك باستخدام استراتيجيات التعلم النشط المختلفة.

2. ت تطوير مناهج رياض الأطفال بما يناسب الإبداع عند الأطفال.

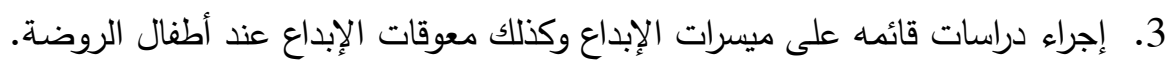

الرابع عشر - المراجع

قائمة المراجع العربية:

إبراهيم، عبدالله علي محمد .(2006). أثر برنامج في الذكاءات المتعددة لمعلمي العلوم في تتمية مهارات التدريس الإبداعي ومهارات حل

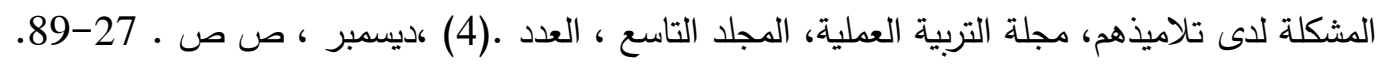

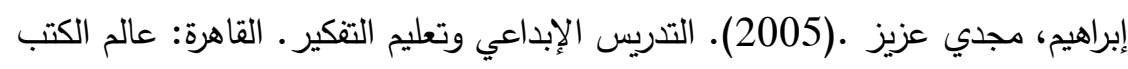

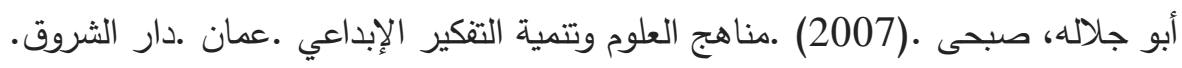

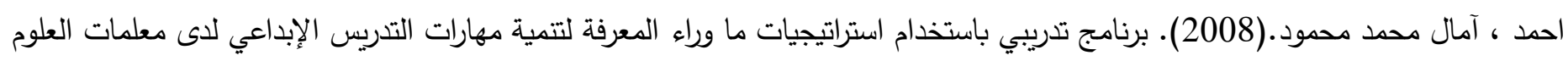

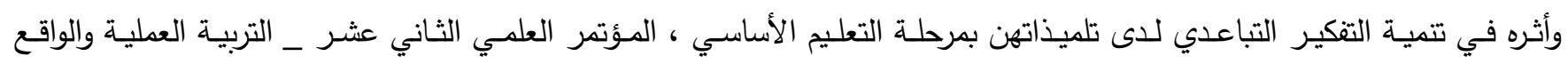

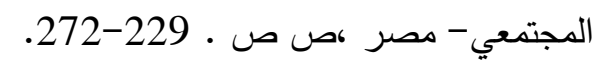

الأستاذ، أحمد.(2013م).أثر استراتيجية التعلم التعاوني في تتمية مهارات التنكير الناقد لدى طلبة الصف العاشر في مبحث الجغرافيا بمحافظات شمال غزة (رسالة ماجستير غير منشورة.)جامعة الأزهر ،غزة.

إسماعيل، حنفي .(2000). فاعلية اكتساب الطلاب المعلمين الأسس المنطقية للبرهان الرياضي وأساليب البرهنة للمشكلات الهندسية في تتمية التفكير الرياضي الإبداعي و مهارات تدريس الهندسة إبداعيا لهم ، مجلة تربويات الرياضيات ، الجمعية المصرية للتربويات الرياضيات، مجلد .(3)، ص ص ص 130-16. 
الأغا، مراد...(2015).فعالية برنامج تدريبي مقترح لمعلمي الرياضيات بالمرحلة الثانوية لتنمية مهارات التدريس الإبداعي لديهم وأثره على إبداع

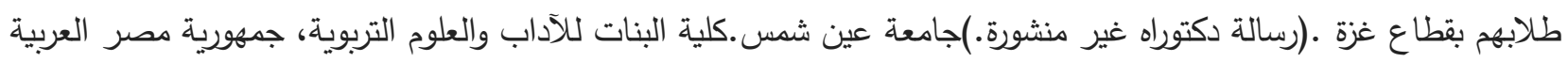
البنغلى ، غدنانه سعيد ؛العبد احمد، أبو السعيد .(1996) التفكير الإبداعي في مجال الدراسات الاجتماعية لدى تلاميذ المرحلة الإعدادية بدولة الدئة

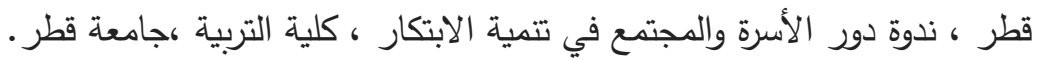

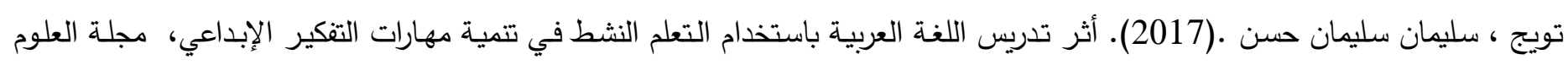

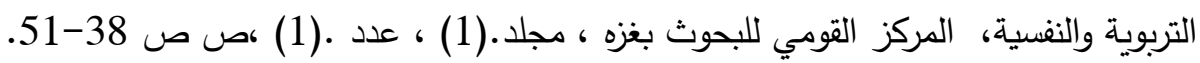

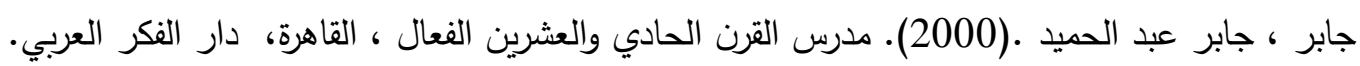
جامعه القدس المفتوحة.(2003). التفكير الإبداعي، منشورات جامعة القدس المفتوحة، فلسطين. جبران، وحيد .(2002) ، التعلم النشط : الصف كمركز تعلم حقيقي ، القاهرة ، دار الفكر العربي .

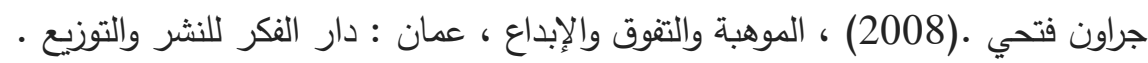

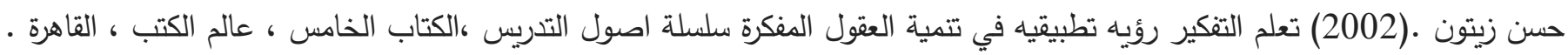

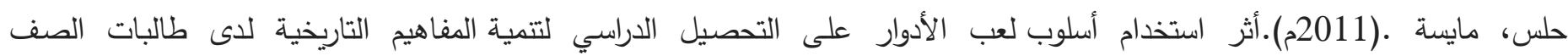
السابع في محافظة غزة.(رسالة ماجستير غير منشورة.)جامعة الأزهر ،غزة. الحلفاوي ، خديجة محمد خير أحمد.(2008). فاعلية برنامج مطور في تتمية بعض مهارات التدريس الابتكاري في مجال العلوم لدى طالبات

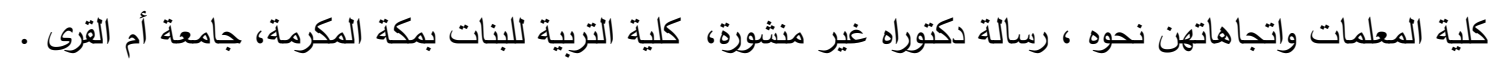

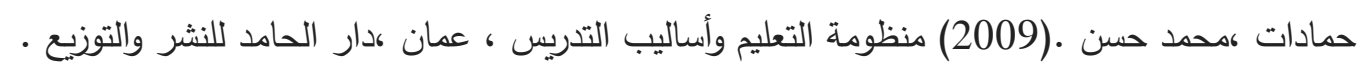
رجائي ، أحمد .(2006). أثر برنامج في النموذجة الرياضية في تتمية استراتيجيات ما وراء المعرفة وسلوك حل المشكلة ومهارات التدريس

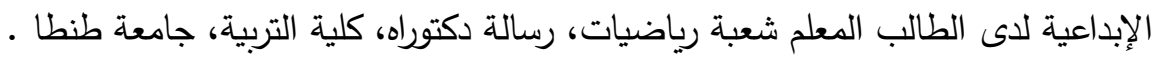

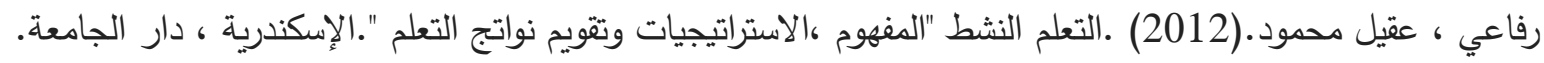
الرفاعي ،عبد الملك طه ـ (2001). فاعلية برنامج التدريس المصغر في تتمية بعض مهارات التدريس الإبداعي لدى الطلاب المعلمين بكلية

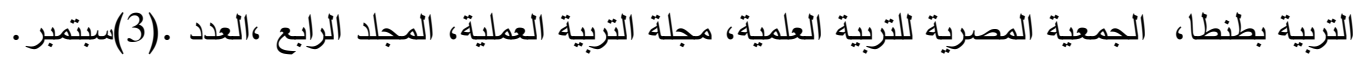

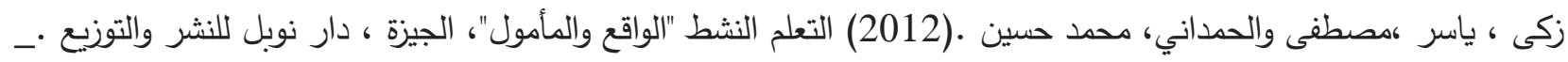

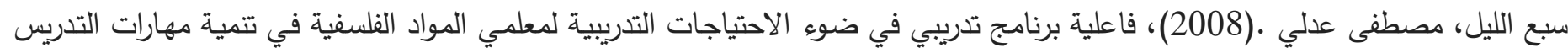
الإبداعي لايهم ومهارات التفكير الإبداعي لدى طلاب المرحلة الثانوية ، رسالة دكتوراه غير منشوره ،كلية التربية ،جامعة الأزهر .

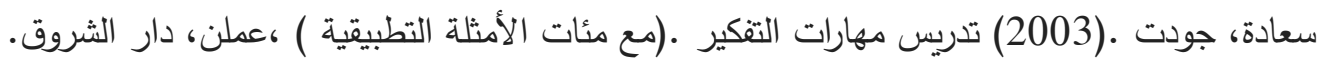

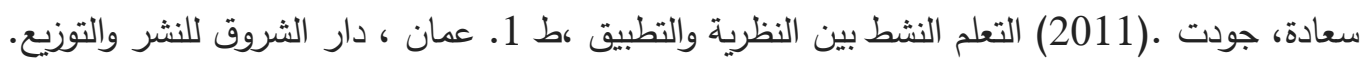
سعيد ، سعيد محمد.( 2002). فاعلية الحقائب التعليمية في تتمية مهارات التدريس الإبداعي لأى معلمي الرياضيات بالمرحلة الابتدائية وعلاقته بالتفكير الإبداعي لاي تلاميذهم ، رسالة دكتوراه غير منشورة، كلية التربية، جامعة بنها.

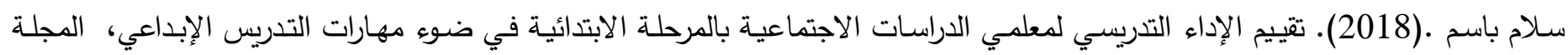

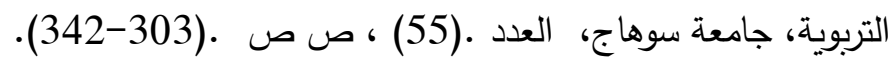
سليمان ، علي محمد حسيني •(2015). برنامج تدريبي مقترح في لتتمية مهارات التدريس الإبداعي لدى معلمي الدراسات الإجتماعية وفاعليته

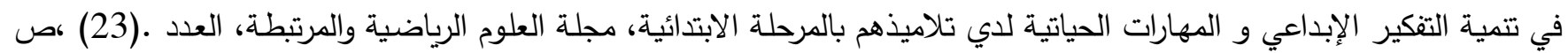
ص ص 
حسن، سناء.(2011) برنامج تدريبي مقترح واثره في تتمية بعض مهارات التدريس الإبداعي في مجال اللغة العربية لاى طالبات كلية التربية ، جامعة أم القري ع .(169).

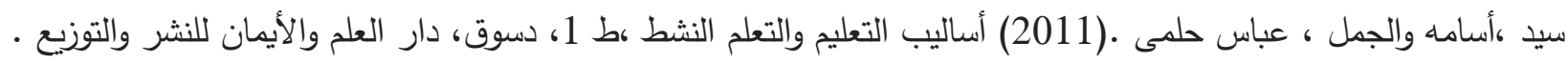
سيف ، نايل يوسف .(2001). فاعلية برنامج تدريبي لتتمية بعض مهارات التدريس الإبداعي لاى معلمي اللغة العربية وأثره على تتمية الإبداع

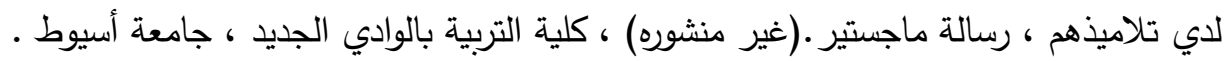

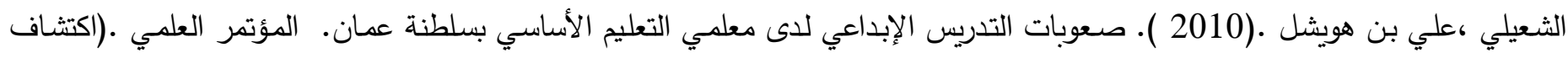

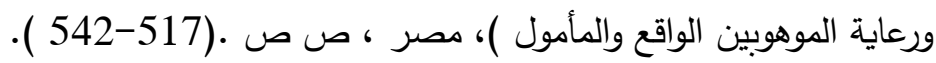

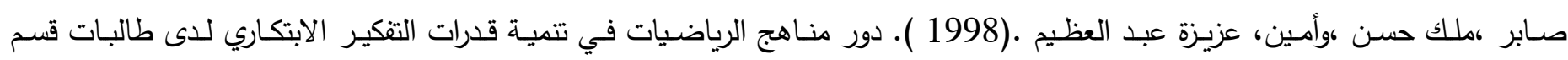

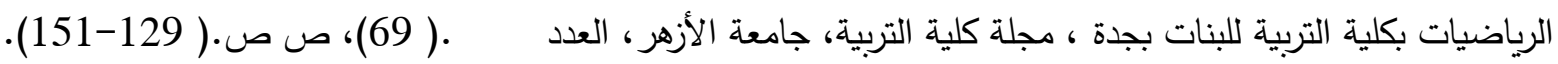

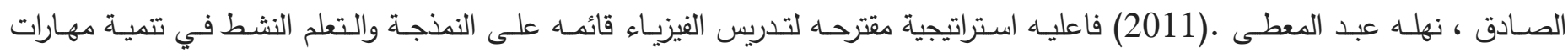

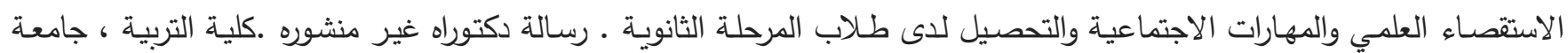
الزقازيق

الطيب بدوي .(2012). فاعلية برنامج مقترح في تتمية مهارات تدريس التفكير الإبداعي والناقد لمعلمي اللغة العربية وأثره على الكتابة الإبداعية

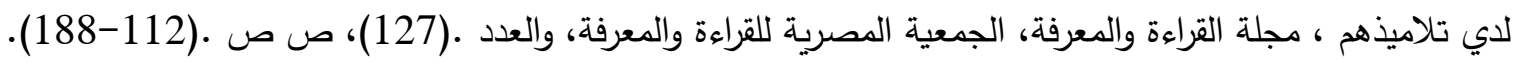

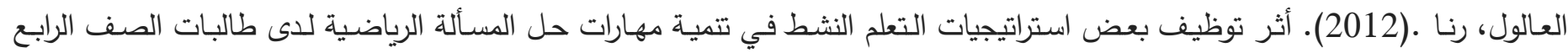
الأساسي بمحافظة غزة.(رسالة ماجستير غير منشورة)جامعة الأزهر ، كلية التربية، غزة.

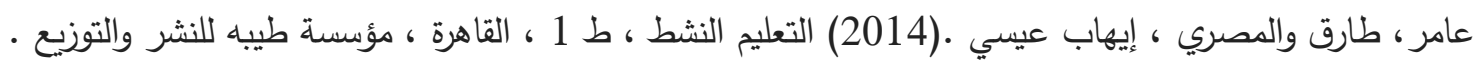

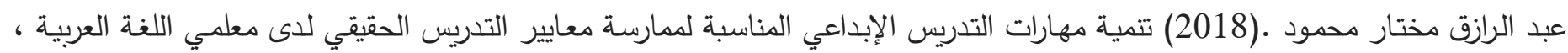

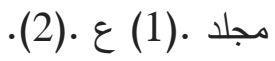
عبد الله ، عبد الهادي.(2007) فاعلية تتوع استخدام استراتيجيات التعلم النشط في تدريس الاقتصـاد على التحصيل والاتجاه نحو دراسـة الاقتصاد لاى طلاب المرحلة الثانوية ـ سلطنة عمان ، مجلة دراسات في المناهج ، يناير ، ع ع (120).

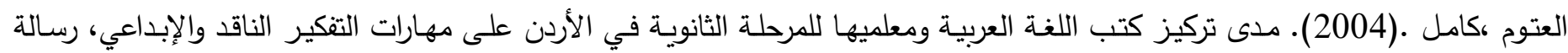
دكتوراه غير منشورة، كلية التربية، الجامعة الأردنية .

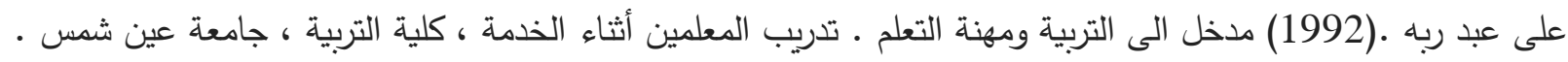
علي ، محمد السيد ،والغنام، محرز .(1998). فاعلية برنـامج مقترح في إكسـاب الطلاب المعلمين في مهارات التدريس الابتكاري وتتميـة

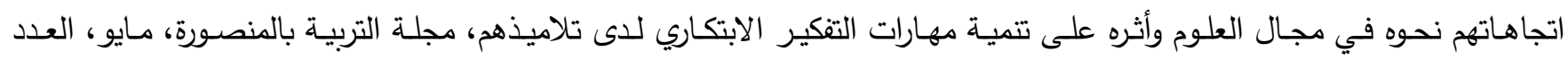

$$
\text { (237). }
$$

عويس ، سالم •(2000) تجارب تربوية عالميه في التعلم النشط ،ط 2 ، رام الله ، مركز الإعلام والتتسيق التربوي .

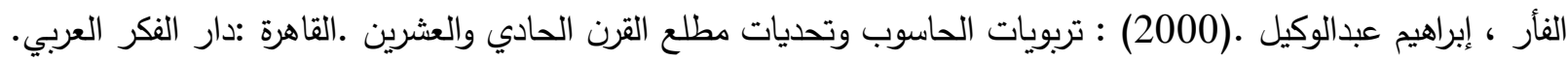

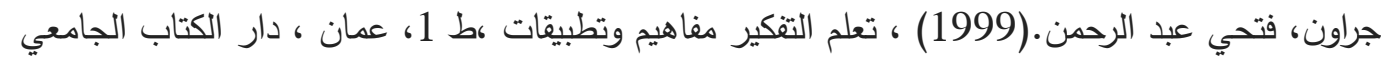

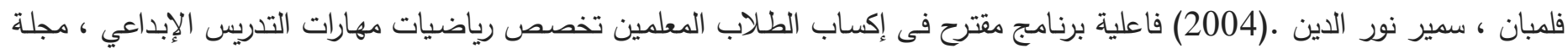

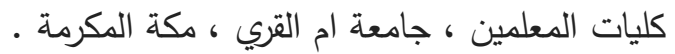
القذافي ، رمضان محمد .(1996).رعاية الموهوبين والمبدعين ، الإسكندرية، المكتب الجامعي الحديث. 


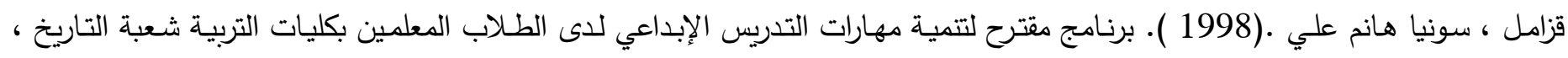

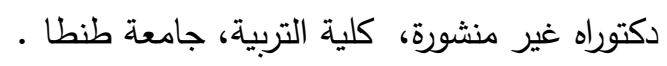

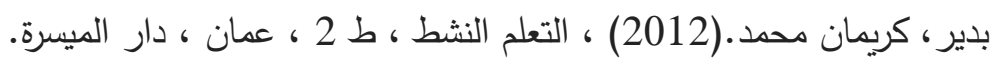
محمود ، عبد الرازق مختار •(2018). تمية مهارات التدريس الإبداعي المناسبة لممارسة معايير التدريس الحقيقي لاى معلمي اللغة العربية.

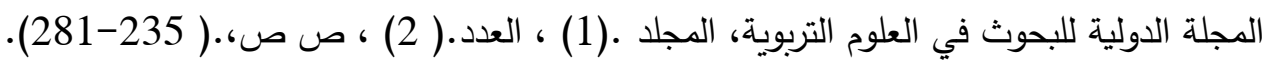
مختار ، هبة اللهه عدلي .(2008) ، اثر مهارات التدريس الإبداعي لدى معلمي العلوم فى تتميـة تحصيل تلاميذ الحلقة الثانيـة من التعليم الأساسي واتجاهاتهم نحو مادة العلوم ، مجلة التربية العلمية ، الجمعية المصرية للتربية العلمية . مختار ، هبه الله عدلي أحمد.(2008). أثر مهارات التدريس الإبداعي لاى معلمي العلوم في تتمية تحصيل تلاميذ الحلقة الثانية من التعليم

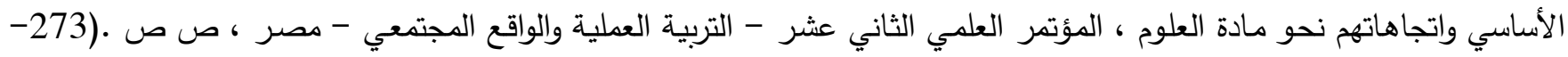
. (306 الأغا، مراد.(2014). فاعلية برنامج تدريبي مقترح لمعلمي الرياضيات بالمرحلة الثانويـة لتتمية مهارات التدريس الإبداعي لديهم بقطاع غزة،

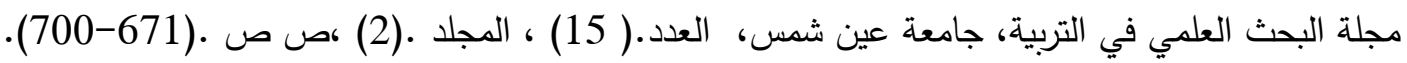

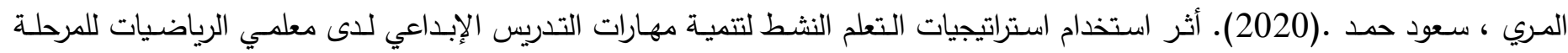

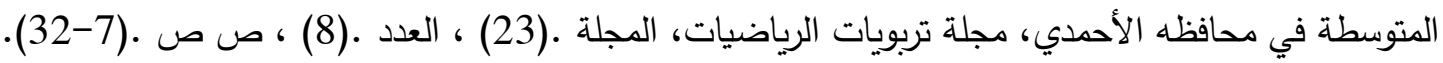
المري ، مباركة صـالح الأكراف ،الباقر ، نصرة رضـا حسن.( 1998). برنامج مقترح لتدريب المعلمات على أساليب تتمية التفكير الابتكاري

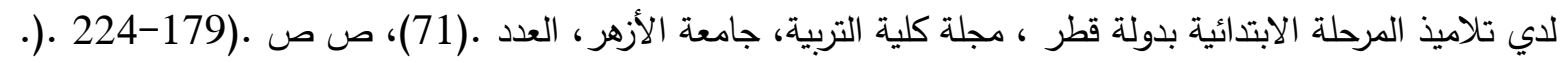

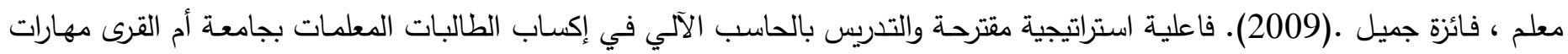
التدريس الإبداعي للتربية الإسلامية وتتمية التفكير الإبداعي لاى تلميذاتهن ، رسالة دكتوراه غير منشورة، كلية التربية، جامعة أم القرى .

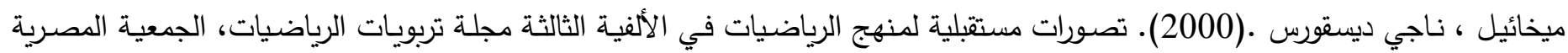
لتزبويات الرياضيات، مج 3 ، يناير ،جامعة الزقازيق.

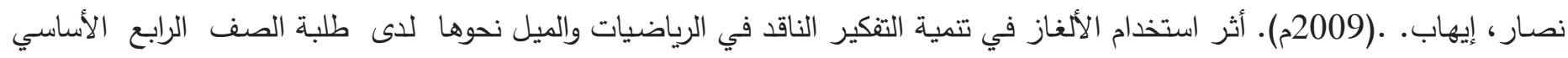

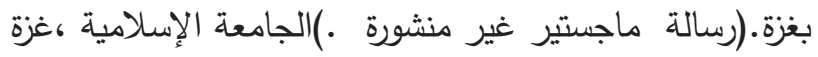

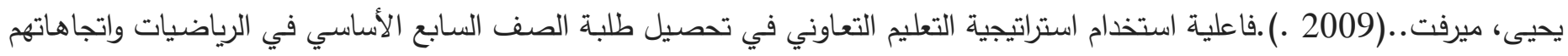
نحوها في مدينة طولكرم •(ر سالة ماجستير غير منشورة)،كلية التربية، جامعة بيرزيت، فلسطين.

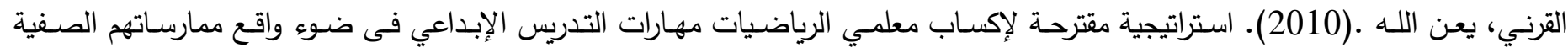

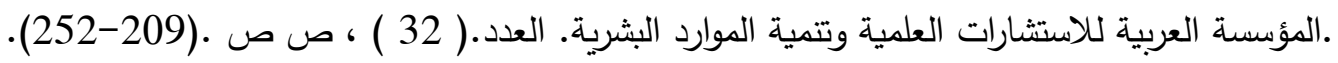


Abu Jalalah, Sobhi (2007), Science Curricula and the Development of Creative Thinking (in Arabic),Amman, Dar Alshroq .

Ahmed, Amal Mohammed Mahmoud (2008): A Training Program Using Metacognition Strategies to Develop Creative Teaching Skills for Science Female Teachers and its Impact on Developing Divergent Thinking among their Students in the Basic Education Stage (in Arabic), the Twelfth Scientific Conference Practical Education and Societal Reality - Egypt, pp. (229 -272).

Al-Agha, Murad (2015). Effectiveness of a Proposed Training Program for High School Mathematics Teachers to Develop their Creative Teaching Skills and its Impact on the Creativity of their Students in the Gaza Strip (in Arabic) (unpublished PhD thesis.) Ain Shams University, Girls' College of Arts and Educational Sciences, Arab Republic of Egypt.

Alagha, Murad. (2014). The Effectiveness of a Proposed Training Program for High School Mathematics Teachers to Develop their Creative Teaching Skills in the Gaza Strip (in Arabic), Journal of Scientific Research in Education, Ain Shams University, No. (15), Vol. (2), pp. (671-700).

Alalul, Rana. (2012). The Effect of Employing Some Active Learning Strategies on Developing Mathematical Problem-Solving Skills among Fourth-Grade Female Students in Gaza Governorate (in Arabic). (Unpublished Master Thesis) Al-Azhar University, College of Education, Gaza.

Al-Atoum, Kamel. (2004). The Extent to which Arabic Language Textbooks and Teachers for Secondary School in Jordan Focus on Critical and Creative Thinking Skills (in Arabic), Unpublished PhD thesis, College of Education, University of Jordan.

Al-Bingley, Ghadnana Saeed; Al-Abd Ahmed, Abu Al-Saeed (1996) Creative Thinking in the Field of Social Studies among Middle School Students in the State of Qatar (in Arabic), Symposium on the Role of Family and Society in Innovation Development, College of Education, Qatar University.

Al-Faar, Ibrahim Abdel-Wakil. (2000): Computer Education and Challenges at the Beginning of the Twenty-first Century (in Arabic). Cairo: , Dar Alfkr Al-Arabiy. Algaddafi, Ramadan Mohammed. (1996). Sponsoring the Talented and Creative People, Alexandria (in Arabic), Modern University Office

Al-Halafawi, Khadija Mohammed Khair Ahmed (2008). The Effectiveness of a Developed Program in Developing Some Innovative Teaching Skills in the Field of Science for Female Teachers College and their Attitudes Toward it (in Arabic), Unpublished PhD Thesis, College of Education for Girls in Makkah Al-Mukarramah, Umm Al-Qura University.

Ali Abd Rabbo. (1992) An Introduction to Education and the Learning Profession. In-Service Teacher Training (in Arabic), College of Education, Ain Shams University.

Ali, Mohammed Al-Sayed, and Al-Ghannam, Mahrez. (1998). The Effectiveness of a Proposed Program in Providing Student Teachers with Innovative Teaching Skills and Developing their Attitudes Towards it in the Field of Science and its Impact on Developing Innovative Thinking Skills among their Students (in Arabic), Journal of Education in Mansoura, May, No. (237), pp. (1-14). 


$$
\begin{aligned}
& \text { منى الزهراني } \\
& \text { فعالية برنامج تدريبي مقترح قائم على التعلم النثط في تنمية مهارات التدريس } \\
& \text { الإبداعي لاى معلمات رياض الأطفال }
\end{aligned}
$$

Alostath, Ahmed (2013), The Impact of Cooperative Learning Strategy on Developing Critical Thinking Skills of Tenth Grade Students in Geography in North Gaza Governorates (in Arabic) (Unpublished Master Thesis) Al-Azhar University, Gaza.

Al-Rifai, Abd al-Malik Taha. (2001). The Effectiveness of the Micro-Teaching Program in Developing Some Creative Teaching Skills among Student Teachers at the College of Education in Tanta (in Arabic), the Egyptian Society for Scientific Education, Journal of Practical Education, Volume IV, No (3) September.

Al-Sadiq, Nahla Abdel-Muti. (2011) The Effectiveness of a Proposed Strategy for Teaching Physics Based on Modeling and Active Learning in Developing Scientific Inquiry Skills, Social Skills and Achievement among High School Students (in Arabic). Unpublished $\mathrm{PhD}$ thesis, College of Education, Zagazig University.

Al-Shuaili, Ali bin Huishel. (2010). Difficulties in Creative Teaching among Basic Education Teachers in Sultanate Oman (in Arabic). Scientific Conference. (Discovering and Caring for the Gifted, Reality and Hope), Egypt, pp. (517-542).

Al-Marri, Saud Hamad (2020). The Effect of Using Active Learning Strategies to Develop Creative Teaching Skills among Middle School Mathematics Teachers in Al Ahmadi Governorate (in Arabic), Journal of Mathematics Education, The Journal. (23), No. (8), p. (7-32).

Al-Marri, Mubaraka Saleh Al-Akraf, Al-Baker, Nasra Reda Hassan. (1998). A Proposed Program for Training Female Teachers on Methods of Developing Innovative Thinking among Primary School Students in the State of Qatar (in Arabic), Journal of the College of Education, Al Azhar University, No. (71), pp. (179-224).

Al-Qarni, Yaen Allah. (2010). A Proposed Strategy for Providing Mathematics Teachers with Creative Teaching Skills in Light of the Reality of their Classroom Practices (in Arabic). The Arab Foundation for Scientific Consulting and Human Resources Development. No. (32), pp. (209-252).

Al-Quds Open University (2003): Creative Thinking (in Arabic), Al-Quds Open University Publications, Palestine.

Abdel-Razek Mukhtar Mahmoud. (2018) Development of Creative Teaching Skills Appropriate to Practice True Teaching Standards among Arabic Language Teachers (in Arabic), Vol. (1) p. (2).

Abdullah, Abdul-Hadi. (2007) The Effectiveness of Diversifying the Use of Active Learning Strategies in Teaching Economics on Achievement and the Trend Towards Studying Economics among Secondary School Students (in Arabic). Sultanate Oman, Journal of Studies in Curricula, January, p. (120).

Amer, Tariq and Al-Masry, Ihab Eissa. (2014), Active L earning (in Arabic),1st Edition, Cairo, Taiba Corporation for Publishing and Distribution.

Badir, Kariman Muhammad. (2012), Active Learning (in Arabic), 2nd Edition, Amman, Maisarah House.

Filmban, Samir Nour El-Din. (2004) The Effectiveness of a Proposed Program in Teaching Student Teachers of Mathematics Specialization Creative Teaching Skills (in Arabic), Journal of Teachers Colleges, Umm Al-Qura University, Makkah Al-Mukarramah. 


$$
\text { فعالية برنامج تدريبي مقترح قائم على التعلم النثط في تنمية مهارات التدريس }
$$

Garawan, Fathy Abdel-Rahman. (1999), Learning to Think, Concepts and Applications (in Arabic), 1st ed. , Amman, University Book House

Gibran, Wahid (2002), Active Learning: The Class as a True Learning Center (in Arabic), Cairo, Dar Alfker Alarabi.

Grwan Fathy (2008), Talent, Excellence and Creativity (in Arabic), Amman: Dar Al-Fekr for Publishing and Distribution.

Halles, Maysa (2011). The Effect of Using Role-playing Style on Academic Achievement to Develop Historical Concepts among Seventh-grade Students in Gaza Governorate. (in Arabic) (unpublished Master Thesis.) Al-Azhar University, Gaza.

Hamadat, Mohammed Hassan (2009). The Education System and Teaching Methods (in Arabic), Amman, Dar Al-Hamid for Publishing and Distribution.

Hassan, Sanaa. (2011) A Proposed Training Program and its Effect on Developing Some Creative Teaching Skills in the Field of Arabic Language among Female Students of the College of Education (in Arabic), Umm Al-Qura University, p. (169).

Hassan Zaitoun. (2002) Learning to Think is an Applied Vision in the Development of Thinking Minds, Fundamentals of Teaching Series (in Arabic), Book Five, The World of Books, Cairo.

Ibrahim, Abdullah Ali Muhammad (2006): The Effect of a Program on Multiple Intelligences for Science Teachers in Developing Creative Teaching Skills and Problem-solving Skills among their Students (in Arabic), Journal of Practical Education, Volume IX, No (4), December, pp. (27-89).

Ibrahim, Magdy Aziz (2005). Creative Teaching and Teaching Thinking. Cairo (in Arabic): The World of Books.

Ismail, Hanafi (2000): The Effectiveness of Student Teachers' Acquisition of the Rationale for Mathematical Proof and Methods of Demonstration of Engineering Problems in the Development of Creative Mathematical Thinking and the Skills of Teaching Engineering Creatively to them (in Arabic), Mathematics Pedagogical Journal, The Egyptian Association for Mathematics Education, Volume (3), pp. (130- 16).

Jaber, Jaber Abdel-Hamid (2000): The Effective Teacher of the Twenty-first Century (in Arabic), Cairo, Dar Alfkr Al-Arabiya.

Mahmoud, Abdel-Razek Mukhtar. (2018). Developing Creative Teaching Skills Appropriate to Practice True Teaching Standards among Arabic Language Teachers (in Arabic). International Journal of Research in Educational Sciences, Vol. (1), No. (2), pp. (235-281).

Mikhail, Nagy Discorus. (2000). Futuristic Representations of the Mathematics Curriculum in the Third Millennium (in Arabic). Mathematics Pedagogy Magazine, the Egyptian Association for Mathematics Education, Volume 3, January, Zagazig University. 
Mukhtar, Heba Allah Adly. (2008), The Effect of Creative Teaching Skills of Science Teachers on the Development of Basic Education Second Stage Pupils Achievement and Their Attitudes Toward Science Subject (in Arabic), Journal of Scientific Education, Egyptian Society for Scientific Education.

Muallem, Faiza Jameel. (2009). The Effectiveness of a Proposed Strategy and Teaching by Computer in Providing Female student Teachers at Umm Al-Qura University with Creative Teaching Skills for Islamic Education and Developing Creative Thinking among their Students (in Arabic). An unpublished PhD thesis, College of Education, Umm Al-Qura University.

Mukhtar, Hebat Allah, Adly Ahmed. (2008). The Effect of Creative Teaching Skills among Science Teachers in Developing the Achievement of Students of the Second Cycle of Basic Education and their Attitudes Towards Science Subject (in Arabic), the Twelfth Scientific Conference - Practical Education and Societal Reality - Egypt, pp. (273-306).

Nassar, Ihab. (2009). The Effect of Using Puzzles on Developing Critical Thinking in Mathematics and the Tendency Towards it among Fourth Grade Students in Gaza (in Arabic). (Unpublished Master Thesis.) Islamic University, Gaza

Owais, Salem. (2000) International Educational Experiences in Active Learning (in Arabic), 2nd ed., Ramallah, Educational Media and Coordination Center.

Qazamel, Sonia Hanim Ali (1998). A Proposed Program for Developing Creative Teaching Skills for Student Teachers in the Colleges of Education, Division of History (in Arabic), unpublished Ph.D., Thesis, College of Education, Tanta University.

Rajaei, Ahmad (2006). The Impact of a Program in Mathematical Modeling in the Development of Metacognition Strategies, Problem-Solving Behavior, and Creative Teaching Skills for the Student Teacher, Mathematics Division (in Arabic), Ph.D. Thesis, College of Education, Tanta University.

Rifai, Aqeel Mahmoud. (2012) Active Learning: The Concept, Strategies and Evaluation of Learning Outcomes (in Arabic). Alexandria, Dar Aljammah.

Saadeh, Jawdat. (2003) Teaching Thinking Skills (in Arabic) (with hundreds of practical examples), Amman, Dar Al Shorouk.

Saadeh, Jawdat. (2011) Active learning between Theory and Practice (in Arabic), ed. 1. Amman, Dar Al Shorouk for Publishing and Distribution.

Sabaa Al-Layl, Mustafa Adly (2008), The Effectiveness of a Training Program in Light of the Training Needs of Philosophical Subject Teachers in Developing Their Creative Teaching Skills and Creative Thinking Skills among High School Students (in Arabic), Unpublished PhD Thesis, College of Education, Al-Azhar University.

Saber, Malek Hassan, and Amin, Aziza Abdel-Azim. (1998). The Role of Mathematics Curricula in Developing the Abilities of Innovative Thinking among Female Students of the Mathematics Department at the College of Education for Girls in Jeddah (in Arabic), Journal of the College of Education, Al-Azhar University, No. (69), pp. (129-151). 


$$
\text { فعالية برنامج تدريبي مقترح قائم على التعلم النثط في تنمية مهارات التريس }
$$

Saeed, Saeed Mohammad. (2002). The Effectiveness of Instruction Kits in Developing Creative Teaching Skills for Primary Mathematics Teachers and Its Relation to Creative Thinking of Their Students (in Arabic), Unpublished PhD Thesis, College of Education, Benha University.

Salam Basem. (2018). Evaluation of the Teaching Performance of Social Studies Teachers at the Primary Stage in the Light of Creative Teaching Skills (in Arabic), The Educational Journal, Sohag University, No. (55), pp. (303-342).

Sayed, Osama and Al-Jamal, Abbas Helmy. (2011) Teaching and Active Learning Methods (in Arabic), 1st Edition, Desouq, Dar Al-Elm and Al-Iman for Publishing and Distribution.

Seif, Nayel Yousef. (2001). The Effectiveness of a Training Program for the Development of Some Creative Teaching Skills for Arabic Language Teachers and its Impact on the Development of Creativity of Their Students (in Arabic), Master Thesis (unpublished), College of Education in the New Valley, Assiut University.

Suleiman, Ali Mohammed Husseini. (2015). A Proposed Training Program in Developing Creative Teaching Skills for Social Studies Teachers and its Effectiveness in Developing Creative Thinking and Life Skills for their Primary School Students (in Arabic), Journal of Mathematical and Related Sciences, No. (23), pp. 1-63.

Tayeb، Badawi. (2012). The Effectiveness of a Proposed Program in Developing the Skills of Teaching Creative and Critical Thinking for Arabic Language Teachers and its Impact on the Creative Writing of their Students (in Arabic), Reading and Knowledge Magazine, Egyptian Organization for Reading and Knowledge, No. (127), pp. (112-188).

Twij, Suleiman Suleiman Hassan (2017): The Impact of Teaching Arabic Language Using Active Learning on the Development of Creative Thinking Skills (in Arabic), Journal of Educational and Psychological Sciences, National Research Center in Gaza, Vol. (1), No. (1), pp. (38-51).

Yahya, Mervat . (2009). The Effectiveness of Using the Cooperative Education Strategy in the Achievement of Seventh-grade Students in Basic Mathematics and their Attitudes Towards it in the city of Tulkarm (in Arabic) (unpublished Master thesis), College of Education, Birzeit University, Palestine.

Zaki, Yasser, Mustafa, and Al-Hamdani, Mohammed Hussein. (2012) Active Learning "Reality and Hope (in Arabic), Giza, Dar Nobel for Publishing and Distribution.

\section{المراجع الأجنبية:}

Armstrong, T. .(2009). Multiple intelligent in classroom. Alexandria, USA: ASCD. Carroll, L. \& Leander, S. .(2001) : Improve Motivation through the Use of Active Learning Strategies. Unpublished Master Dissertation Sainm Xavier University.

De , T. \& Jorge , P. .(1999). Proposal for a national program on Accelerate literacy, J ,N ,A, ErK ED 295053.

Eison , j, A, Donwell , C. C. .(1991).Active Learning: Creating Excitement in the Classroom. Washington , D.C.Geoorge washington Uni .Press.

Fazelian,.(2012), Creativity in Schools, World Conference on Psychology and Sociology, Social and Behavioral Sciences 82,719-723, ww.sciencedirect.com. 


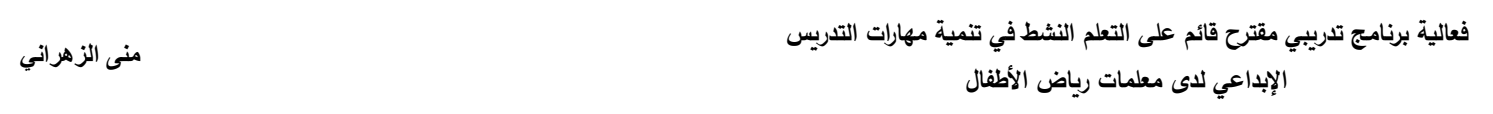

Felder ,M, Brent,R..(1997). Effective teaching work shop. North Carolina; north Carolina state. University press.

Felder, R .M .\& Brent, R ..(2005). Understanding student differences. Journal of Engineering Education, 94 (1), $57-72$.

Harris, J..(2005).Teaching Creativity. New York: Cambridge University, press.

Joseph ‘C. .(2000). Teaching Classroom Educators How Tope More Effective and Creative Teaches 'Journal of Research in Mathematics Education ،120 .(4) 265-275.

Mei-Shiu , Chiu (2009). Approaches to the teaching of creative and non - creative mathematical problems. International journal of Since and Mathematics Education, 7 .(1) ,55-79,Feb

Meyers, Jones,B..(1993) promoting active learning strategies for the college class room, san Francisco ,Jossey.Bass Inc.

Wing,A..(2001). An innovative teaching practice: scientific investigation as a creative teaching method in primary education, Asia -pacific on science learning and teaching, 2.(2), article8. 